\title{
Wind sensitivity of the inter-ocean heat exchange
}

\author{
By HANNA CORELL ${ }^{1 \star}$, JOHAN NILSSON ${ }^{1}$, KRISTOFER DÖÖS ${ }^{1}$, and GÖRAN BROSTRÖM ${ }^{2}$ \\ ${ }^{1}$ Department of Meteorology, Stockholm University, Sweden; ${ }^{2}$ Norwegian Meteorological Institute, Oslo, Norway
}

(Manuscript received $\mathrm{xx} \mathrm{xx} \mathrm{xxx}$; in final form $\mathrm{xx} \mathrm{xx} \mathrm{xxxx}$ )

\begin{abstract}
An idealised two-basin model is used to investigate the impact of the wind field on the heat exchange between the ocean basins. The scalar potential of the divergent component of the horizontal heat flux is computed, which gives a "coarse-grained" image of the surface heat flux that captures the largescale structure of the horizontal heat transport. Further the non-divergent component is examined, as well as the meridional heat transport and the temperature-latitude overturning stream function. A sensitivity analysis examines the heat transport response to changes in wind stress at different latitudes. The results are compared with results from an eddy-permitting global circulation model.

The westerly wind stress over the Southern Ocean has two effects: a local reduction of the surface heat loss in response to the equatorward surface Ekman drift, and a global re-routing of the heat export from the Indo-Pacific. Without wind forcing, the Indo-Pacific heat export is released to the atmosphere in the Southern Ocean, and the net heat transport in the southern Atlantic is southward. With wind forcing, the Indo-Pacific export enters the Atlantic through the Aghulas and is released in the Northern Hemisphere. The easterlies enhance the poleward heat transport in both basins.
\end{abstract}

* Corresponding author.

Department of Meteorology, Stockholm University, S-106 91 Stockholm, Sweden, e-mail: hanna@misu.su.se (C) 0000 Tellus 


\section{Introduction}

The thermohaline circulation and the pathways of the global ocean heat transport play a significant role in determining the climate. The northward reach of the Atlantic basin and the high salinity of the water give, through buoyancy exchange at the sea surface, the means of deep-water formation. This closes a circuit in which a net northward transport of heat in the Atlantic plays a crucial part. The sources of this heat and the mechanisms controlling the transport have long been an issue of debate (cf. Kuhlbrodt et al., 2007, for a review).

Gordon (1986) summarised the division between the so called cold-water path flowing through Drake Passage and the warm-water path, being a part of the Conveyor Belt and passing through the Agulhas current on its way into the Atlantic. He concluded that the water running through Drake Passage is not warm enough to be the sole supplier of the upper layer return flow that is needed to feed the North Atlantic Deep Water (NADW) production. The bulk of the return flow has to reside within the thermocline layer. The only large enough source of such water, according to Gordon (1986), is the Indian Ocean water entering the Atlantic by the Agulhas rings. This would indicate preponderance for the warm water path. Lagrangian studies using trajectories computed from velocity fields simulated by ocean general circulation models confirm these results with a dominating warm water path over the cold water path (Döös, 1995; Blanke et al., 2001).

The traditional view of the heat transport assigns the main part of the responsibility of the polward heat transport to the meridional overturning. Changes in the abyssal circulation have been suggested to have the ability to influence the regional climate in the north of Europe, and a collapse of the same may significantly alter the circulation patterns globally. A recent study by Boccaletti et al. (2005) proposes that this attention towards the deep circulation is disproportional in comparison to its influence in the heat transport. The main part of the transport is instead performed by much shallower circulation. This corroborates the finding of Klinger and Marotzke (2000) that in the equatorial latitudes the wind-driven circulation stands for a significant contribution to the meridional heat transport in the ocean.

Toggweiler and Samuels $(1995 ; 1998)$ introduced the idea that the meridional overturning circulation in the Atlantic is chiefly driven by wind forcing over the Southern Ocean. They attributed this connection to the presence of Drake Passage and the dynamic constraints that a circumpolar channel imposes on the meridional flow. An increased northward Ekman transport pushes surface waters into the Atlantic and enhances both the over all 
heat transport, and the meridional overturning by increasing the upwelling of deep water. Interestingly, Tsujino and Suginohara (1999) showed that this "Drake Passage" effect could be obtained in a model without a circumpolar channel. A positive surface heat flux anomaly in the area of the wind forcing is balanced by increased cooling elsewhere, and thus leads to a positive basin-scale overturning anomaly. Klinger et al. $(2003 ; 2004)$ showed that this enhanced remote overturning can be produced by an increase in either the subpolar wind stress or the diapycnal mixing. Furthermore, Klinger et al. (2004) used scaling arguments to show that sufficiently strong subpolar westerlies should produce a positive surface heating anomaly that cannot be balanced by local cooling, and hence requires a remote overturning response carrying heat across the equator. This is primarily a thermodynamic argument, which does not invoke the dynamical constraint due to a circumpolar channel that is essential for the remote overturning response envisioned by Toggweiler and Samuels (1995). Moreover, the "Darke Passage" effect tends be weak in models with weak restoring of the surface temperature (Rahmstorf and England, 1997; Bugnion et al., 2006). It should also be noted the "Darke Passage" effect disregard the role played by eddies. In the Southern Ocean, the eddies are instrumental for the meridional transport of heat and properties (see e.g. Marshall and Radko, 2006). In fact when the overturning circulation is viewed from an isopycnal perspective, the eddy-induced transports tend to cancel the wind-driven Eulerian Deacon cell (Döös and Webb, 1994; Marshall and Radko, 2006; Döös et al., 2008). Thus, the link between the poleward surface Ekman drift in the Southern Ocean and the meridional overturning in the Atlantic appears to be less direct than originally proposed by Toggweiler and Samuels (1995).

Two views of how the winds over the Southern Ocean affect the Atlantic meridional overturning and its attendant heat transport can be distinguished. First, the idea of Toggweiler and Samuels (1995) in which wind-forced upwelling of dense water in the Antarctic Circumpolar Current directly feeds the sinking in the North Atlantic. In this scenario, the Indo-Pacific basin plays a passive role. A different view is that the wind forcing primarily act to steer the outflow of warm water from the Indo-Pacific around South Africa into the Atlantic (e.g. Gordon, 1986; Döös, 1995; Bugnion et al., 2006). In this scenario, diapycnal mixing and surface heating creates thermocline water in the Indo-Pacific that in the absence of wind forcing would cool and sink in the high southern latitudes.

The mechanisms behind the wind-induced remote forcing of the meridional overturning circulation, and its influence over the global heat transport patterns, to a large extent remains (c) 0000 Tellus, 000, 000-000 
to be explained. The present work will in a way connect back to the question posed by Gordon (1986), i.e. where the heat transported into the Atlantic originates, and which path it takes. A series of numerical experiments are made with a highly idealised ocean circulation model to examine how changes in wind patterns and strength alter the pathways of the heat transport in the ocean. Special attention is directed towards the heat exchange between the Atlantic and the Indo-Pacific basins, and to what extent the heat transport can be re-routed by the wind forcing over the Southern Ocean. The model geometry and forcing are chosen to be the simplest possible that still produces the dynamical features needed to study interbasin heat exchange. Specifically, an idealised two-basin geometry is employed that is similar to the simplified basin configurations used by e.g. Hughes and Weaver (1994), McDermott (1996), Hirabara et al. (2007), and De Boer et al. (2008). These studies focused primarily on factors that control the strength of the Atlantic meridional overturning, whereas the present focus is on interbasin heat transport.

In the present study, several methods are employed to analyse the heat transport and the interbasin exchange patterns. One specific aim is to examine what information the depthintegrated horizontal heat transport vector reveals about the interbasin heat exchange. In this context, the scalar potential of the divergent component of the heat transport vector is calculated and examined. This interesting approach was used by Trenberth and Solomon (1994) but has otherwise hardly been used among oceanographers. Also, the utility of the stream function of the non-divergent heat transport vector is examined. In addition, the heat transport is analysed on the basis of the meridional stream functions in the temperaturelatitude plane. The results from the idealised model are, when relevant, compared to output from an advanced, high resolution global ocean circulation model. The remainder of the paper is structured as follows: Section 2 presents the idealised and high-resolution models. The heat transport is examined from a variety of perspectives in section 3 and a sensitivity analysis of the wind response in the idealised model is undertaken in section 4 . The results are summarised and discussed in the concluding section.

\section{The model experiments}

\subsection{The idealized two-basin model}

The experiments are made with the MIT general circulation model (Marshall et al., 1997), a finite-volume, incompressible Navier-Stokes model, using a simplified topography 
and idealised forcing. The domain and the experiment setup are chosen to be the simplest possible that still produces the dynamical features needed to investigate the effect of the wind forcing on the paths of the global heat transport; in particular the connection between the ocean basins.

The model domain is a two-basin configuration with a narrower "Atlantic" basin and a broader "Indo-Pacific". It is similar to that used by McDermott (1996), and can be seen in Fig. (1). The two basins are connected through the "Southern Ocean", which have a periodical border at "Drake Passage", allowing for a circumpolar flow. The resolution is $2^{\circ} \times 2^{\circ}$, reaching from $60^{\circ} \mathrm{N}$ to $60^{\circ} \mathrm{S}$ in latitude, and $0^{\circ}-182^{\circ}$, thus covering a "half-earth" in longitude. The Atlantic basin covers $60^{\circ}$ of these $182^{\circ}$, and the Indo-Pacific $120^{\circ}$. The remaining area is the land dividing the basins. The Indo-Pacific only reaches to $48^{\circ} \mathrm{N}$. The shorter land barrier mimicking Africa has a southward reach of $26^{\circ} \mathrm{S}$. The circumpolar channel at Drake Passage extends between $44^{\circ} \mathrm{S}$ to $60^{\circ} \mathrm{S}$. This is an exaggeration; the actual latitudinal extent of Drake Passage at this resolution would be about half of this. The domain has 26 vertical levels; the levels being shallower near the surface and successively deeper closer to the bottom. The total depth is 4000 meters everywhere but in the Drake Passage, where the threshold depth is 2600 meters. The domain walls are vertical, i.e. there are no continental slopes.

The MIT model is forced with idealised zonal wind fields, mimicking the shape of the annual-mean surface wind. Three different wind cases are tested; a somewhat realistic wind profile with stronger westerlies in the southern hemisphere than in the northern, a symmetric wind case, and a case with wind only over the Southern Ocean, see Fig. 2. The wind profile with realistic proportions is based on climatology by Hellerman and Rosenstein (1983) and will hereafter be denoted "realistic" wind. All cases were performed with $0.25,0.5,1$ and 2 times the normal wind strength. Note that the normal wind strength for the symmetric wind case is set after the wind strength on the northern hemisphere. The three cases are compared to a reference case with no wind.

The density in the model depends only on temperature and is given by a linear equation of state: $\rho=\rho_{0}(1-\alpha T)$, where $\rho_{0}$ is a constant reference density and $\alpha=2 \cdot 10^{-4}{ }^{\circ} \mathrm{C}^{-1}$. The sea surface temperature is relaxed towards a reference temperature given by $T_{\text {ref }}=$ $\Delta T\left[\cos \left(\pi \theta / \theta_{0}\right)+1\right] / 2$, where $\Delta T=20^{\circ} \mathrm{C}, \theta$ the latitude, and $\theta_{0}=60^{\circ}$. The restoring time scale is 50 days, acting on the $50 \mathrm{~m}$ deep uppermost grid cell, which implies that the surface heat flux is given by $Q=-\lambda\left(T_{r e f}-T\right)$ with $\lambda=50 \mathrm{~W} \mathrm{~m}^{-2}{ }^{\circ} \mathrm{C}^{-1}$. Note that the modest (C) 0000 Tellus, 000, 000-000 
value of the equator-to-pole temperature difference is chosen to obtain a reasonable overall density difference in the absence of salinity variations.

The horizontal $\left(A_{h}\right)$ and vertical $\left(A_{v}\right)$ eddy viscosities are $5 \cdot 10^{3} \mathrm{~m}^{2} \mathrm{~s}^{-1}$ and $10^{-3} \mathrm{~m}^{2} \mathrm{~s}^{-1}$, respectively. The vertical diffusivity $\kappa_{v}$ is uniform and given the value $2 \cdot 10^{-5} \mathrm{~m}^{2} \mathrm{~s}^{-1}$. To minimise spurious diapycnal mixing, due to horizontal diffusion across sloping density surfaces, we employ the Gent-McWilliams scheme, (Gent and McWilliams, 1990). This scheme represents isopycnal mixing of tracers by baroclinic eddies. In all simulations, the isopycnal diffusivity is set to $10^{3} \mathrm{~m}^{2} \mathrm{~s}^{-1}$, the maximum slope is set to $10^{-2}$ and a tapering scheme is employed. The experiments are integrated forward in time about 2000 years, until a stationary state is achieved.

\subsection{The OCCAM model}

The OCCAM model (Coward and de Cuevas, 2005; Marsh et al., 2005a;b) was developed with the aim to help the study of the data coming from the World Ocean Circulation Experiment (WOCE). In this study we use data from the OCCAM model to compare with the findings of our highly idealised experiments with the MIT model. The OCCAM model is a fully global z-level primitive equation model, which includes an explicit free surface, a KPP mixed layer, an isoneutral mixing scheme, a partial bottom cell scheme and a sea-ice model with elastic-viscous-plastic dynamics and three layer thermodynamics. The eddypermitting horizontal resolution $0.25^{\circ} \times 0.25^{\circ}$ is combined with high vertical resolution, comprising 66 levels with 14 in the top $100 \mathrm{~m}$. Surface forcing was provided by a set of high frequency atmospheric fields and a realistic bulk formulation. Six-hourly fields of wind speed, air temperature, specific humidity and sea level pressure, and monthly average fields of precipitation, cloudiness and incoming short-wave radiation were combined with the model top level temperature to compute the momentum, heat and freshwater fluxes to be applied at each time step. The models top level (i.e. the top $5 \mathrm{~m}$ ) is relaxed to climatology (Levitus et al., 1994), for heat and fresh water fluxes, with a timescale of 7.5 days. The input data for the period 1985-2003 were supplied by NCAR, and the data and formulation are described in Large et al. (1997). A detailed model description is given in Coward and de Cuevas (2005).

We have calculated stream functions, the heat potential and heat trajectories using the time dependent velocity and temperature fields simulated for the years 1991-2002. The model fields from every 5 days were used. 


\subsection{The steady-state characteristics; the idealised model}

The idealised coarse-resolution two-basin model is designed to qualitatively capture some key features of the real global-scale ocean circulation (see e.g. McDermott, 1996). For instance, the "Indo-Pacific" basin is chosen to be wider, which tend to make the net lowlatitude upwelling and heat uptake greater there than in the smaller "Atlantic" basin. Also the fact that "America" extends further to the south than "Africa" has an important effect on the interbasin circulation. When interpreting the model results, however, there are a number of simplifications that must be kept in mind. To begin with, we use a linear equation of state, which depends only on temperature. This implies that the effects of salinity variations on the large-scale circulation are missing. The limited northward extension of the "Indo-Pacific" is a crude way to account for dynamical effects due to the salinity difference between the North Atlantic and the North Pacific; see the discussion below. Similarly, the target restoring $\Delta T$ of only $20^{\circ}$ rather than around $25^{\circ}$, is chosen to compensate for the lack of salinity influence on the equator-to-pole density difference. Thus, a reproduction of the key water masses in the World Ocean and their vertical layering cannot be expected from the present model. Further, the extremely idealised basin geometry, which is only a "half world" in longitude, and the use of vertical side boundaries should be recalled when comparing the present results with those from coarse-resolution models with realistic basin geometry. Moreover, the surface wind stress is time independent and zonally-symmetric, which implies that wind forcing is identical over the two basin. The horizontal resolution of $2^{\circ} \times 2^{\circ}$ in combination with the GM-scheme and a relatively high lateral viscosity yield, at the end of the model integrations, time-independent flows without baroclinic eddies. Despite the simplicity of the model, it captures several qualitative features of the large-scale ocean circulation that are briefly described below.

In the model, deep water is formed in the "North Atlantic", (NADW), as well as in the "Southern Ocean", (Antarctic Bottom Water, AABW); see Fig. 3. The AABW is slightly colder (i.e. denser) than the NADW, reflecting a weaker poleward surface flow in the south which causes the surface temperature there to lay closer to the relaxation temperature. The limited northward extension of the "Indo-Pacific" makes the surface water warmer (i.e. less dense) there than in the "North Atlantic". This acts to prevent deep sinking in the "IndoPacific", where intermediate water masses are formed in the high northern latitudes (see e.g. Hughes and Weaver, 1994; De Boer et al., 2008). As examined by Hughes and Weaver (c) 0000 Tellus, 000, 000-000 
(1994), however, the features of the conveyor-like circulation with sinking in the "North Atlantic" and upwelling in the "Indo-Pacific" are, under equatorially-symmetric restoring boundary conditions, not solely controlled by the difference in northward extension between the two idealised basins. They found that also differences in basin widths and southward extension of "Africa" and "America" affect the character of the interbasin circulation.

The overturning stream functions for the realistic wind case is presented in Fig. 3. The Atlantic basin has 10.4 Sv (Sverdrups, $10^{6} \mathrm{~m}^{3} \mathrm{~s}^{-1}$ ) of sinking in the north, and the deep Atlantic outflow, defined as the water of North Atlantic origin leaving the basin at at $26^{\circ}$ south, is $5.6 \mathrm{~Sv}$. The "Indo-Pacific" has equatorially-concentrated upwelling and a weaker overall flow. There is a "Deacon Cell" of $13.6 \mathrm{~Sv}$ in the "Southern Ocean". For comparison the overturning stream function for the case with no wind is shown in Fig. 4. The "Antarctic Circumpolar Current" (ACC) strength measured in "Drake Passage" is $60 \mathrm{~Sv}$; the corresponding value for the case without wind is $18 \mathrm{~Sv}$. In the "Southern Ocean", the combined meridional overturning circulation of the Eulerian and GM velocities captures some broad features of observationally-based flow estimates (see e.g. Marshall and Radko, 2006; Döös et al., 2008): The wind-forced "Deacon Cell" is partly reversed by a counter-rotating eddydriven cell, which here is represented by the GM bolus velocities. The residual circulation (i.e. GM plus Eulerian, not shown) tend to reveal a two cell structure in which "North Atlantic" deep water is brought southward towards the surface and feeding equatorward return flows of both "AABW" bottom water and intermediate water (this is hinted in Fig. 3).

Figure 1 depicts the temperature and flow fields at 300 meters depth, for the realistic wind case and the case with no wind. At similar latitudes, the thermocline temperatures in the "Atlantic" tend to be colder than in the "Indo-Pacific". In the case with wind forcing the thermocline tends to be deeper, resulting in higher temperatures at 300 meters depth. Figures 5 and 1 reveal some "Agulhas" leakage and retroflection near the tip of "Africa", terms which here characterise the continuation of the "Indo-Pacific" western boundary current after it separates from "Africa" (see e.g. Gordon, 1986; De Ruijter et al., 1999). Figure 1 also indicates that the "Agulhas" leakage from the "Indo-Pacific" to the "Atlantic" is more pronounced in the presence of wind forcing. In the present coarse-resulotion model, where the Rossby number near the tip of "Africa" is on the order of 0.05 or less and the flow is steady, the "Agulhas" dynamics is controlled foremost by vortex stretching and lateral friction, rather than by inertial effects such as advection of relative vorticity (see e.g. De Ruijter et al., 1999; Dijkstra and De Ruijter, 2001, and references therein). Figure 5 shows 
that the retroflection is a baroclinic feature: It is visible in the surface pressure field, which roughly delineates the thermocline depth, but completely absent in the barotropic stream function, which reveals a "super gyre" in the subtropical southern hemisphere that spans both basins (De Ruijter et al., 1999; LaCasce and Isachsen, 2007). The eastward mean flow is strong enough to arrest westward-propagating baroclinic Rossby waves, a feature which is essential for keeping the depressed thermocline off "Africa" from drifting westward as a long baroclinic Rossby wave. A closer inspection of velocity, temperature, and pressure fields suggests that there is both a geostrophic and a viscous ageostrophic flow component in the "Agulhas" leakage into the "Atlantic". In the OCCAM model and in reality, the leakage tends to accomplished by intermittent shedding of ring-like eddies that drift into the Atlantic (see e.g. De Ruijter et al., 1999). However, the details of the "Agulhas" dynamics is not pursued further here. As concluding remark we note that the use of vertical side boundaries and highly idealised coast lines are known to adversely affect separation and retroflection of Agulhas-like currents in model simulations (see e.g. Matano, 1996; De Ruijter et al., 1999; Dijkstra and De Ruijter, 2001; Nøst et al., 2008). Despite this, the present model yields some retroflection of the "Agulhas" current, but its contribution to the inter-ocean heat transport may well depend on the details of the topography and the horizontal resolution of the model. For this reason, the comparison of the heat transport patterns between the idealised model and the OCCAM model will prove to be valuable.

\subsection{The steady-state characteristics; the OCCAM model}

A number of studies have been devoted to analyses of the OCCAM model (see e.g. Fox et al., 2000; Marsh et al., 2005a;b; Döös et al., 2008), so only a brief summary is provided here. Some deficiencies in the representation of the deep overflows at high latitudes and the exact path of the Gulf Stream are found, but these are common in this class of models and at this resolution. The ACC strength in the Drake Passage is $153 \mathrm{~Sv}$, which slightly larger than observational estimates (Fox et al., 2000). Beside these issues, the simulated rates of water transformation compare favourably with observational estimates.

The overturning stream function simulated by OCCAM is presented in Fig.

6. The figure shows the average of all stream functions calculated for the individual 5 days fields from 1991-2002. By comparing this with the stream functions from the idealised model with realistic winds (Fig. 3), it is possible to see what features we capture and miss by 
simplifying the dynamics, the forcing fields and bathymetry. The idealised model captures qualitatively the main features of the Conveyor Belt, with a NADW production in the North Atlantic and a corresponding upwelling of these waters in the Southern Ocean and Indo-Pacific (Döös and Coward, 1997). It also simulates the tropical cells and the Deacon Cell. Apart from the detailed structures, the only main feature the idealised model does not reproduce in a satisfying way is the AABW. As noted above, the idealised model have a linear equation of state, and that the density in the model is a linear function of the temperature alone. The non-linear effects and the salinity influence on the density plays, however, an important role in separating the water masses in OCCAM as well as in the real ocean.

\section{Analysis of the heat transport}

To analyse how the wind forcing affects the circulation and the heat flux in the idealized two-basin model, it is instructive to contrast the cases with and without wind forcing. In the following sections the case denoted "realistic wind" is compared to the case with no wind, if nothing else is stated. A main objective is to examine the interbasin heat exchange. In this context, the meridional heat transport is a useful starting point. Further, the verticallyintegrated horizontal heat flux vector field, which can be decomposed in a divergent and a non-divergent component, will be considered. In addition, a meridional-temperature stream function, which is directly related to the meridional heat transport, will be analysed.

\subsection{The meridional heat transport}

The meridional heat transport is defined as

$$
H(y)=\rho c_{p} \int_{x_{W}}^{x_{E}} \int_{-H}^{0} v(x, y, z) T(x, y, z) d z d x,
$$

where $v$ is the meridional velocity with the bolus velocity from the Gent-McWilliams scheme added, $T$ is the temperature and $\rho$ is the water density, $c_{p}$ is the heat capacity of the water and $x_{E}$ and $x_{W}$ are the eastern and western boundaries. Figure 7 shows the meridional heat transport.

In the absence of wind forcing, the total poleward heat transport is nearly antisymmetric with respect to the Equator. It is noteworthy that the net heat flow is southward in the south Atlantic, i.e. the opposite to the present situation in the real ocean. Primarily, the 
wind forcing introduces a hemispheric asymmetry in the total heat transport by strengthening/weakening the poleward heat transport in the northern/southern hemisphere. The Atlantic and the Indo-Pacific respond in quite different ways to the wind forcing. The southward heat export from the Pacific is hardly affected by the wind forcing, whereas the wind reverses the direction of the heat transport in the South Atlantic. In the Pacific, the main wind response is enhanced poleward heat transport near the Equator, a feature related to a shallow wind-driven tropical cell (Held, 2001; Klinger and Marotzke, 2000).

In the model the outflow from the Atlantic is comprised by cold deep water as well as by relatively warm surface water, while the balancing inflow consists of water of intermediate temperatures. An inspection of the horizontal velocity field of the no wind case, see Fig. 1 bottom panel, reveals that the inflow originates primarily from the Southern Ocean, entering the Atlantic along the western boundary. This flow pattern resembles the "cold-water path" circulation in the real Atlantic, as described by Gordon (1986). As shown in Fig. 7, the relatively low temperature of this inflow results in a net heat transport out of the Atlantic, despite the southward export of cold Atlantic deep water.

Further, figure 7 shows that the presence of wind forcing reduces the southward heat transport and consequently also the surface heat loss in the Southern Ocean. This change is compensated for by an enhanced northward heat transport in the Atlantic. The associated rearrangements of the flow field can be traced in Fig. 1. To begin with, the formation and export of Atlantic deep water is enhanced by the wind forcing (this is seen in Fig. 13, introduced later). Further, the temperature of the warmest in-flowing water is increased (i.e. the flow-weighted inflow temperature is higher). As can be seen in Fig. 1, the inflow of thermocline water to the Atlantic tends to come from the Pacific, entering the Atlantic near the tip of Africa. This change of the thermocline circulation causes the rise of the inflow temperature and results in a flow pattern resembling the "warm-water path" circulation in the real ocean (Gordon, 1986; Döös, 1995).

A straightforward interpretation of the heat transport results shown in Fig. 7 is that the wind forcing re-directs the Pacific heat export from the Southern Ocean to the Atlantic, where it is released to the atmosphere in the Northern Hemisphere. Although the meridional heat transports, examined so far, yield limited information on the interbasin heat exchange, the analyses presented below will corroborate this interpretation.

(c) 0000 Tellus, 000, 000-000 


\subsection{The horizontal heat flux vector}

Here the horizontal heat flux vector will be examined, which provides a two-dimensional view of the heat transport. By integrating the temperature equation vertically over the full depth one obtains

$$
c_{p} \rho \frac{\partial}{\partial t} \int_{-H}^{0} T d z=-\nabla \cdot \mathbf{F}-Q .
$$

Here, $Q$ is the surface heat flux (defined in section 2.1) and the depth-integrated horizontal heat flux $\mathbf{F}$ is defined by

$$
\mathbf{F}=c_{p} \rho \int_{-H}^{0}\left(\mathbf{v}+\mathbf{v}_{*}\right) T d z
$$

where $\mathbf{v}$ and $\mathbf{v}_{*}$ are the Eulerian and the GM bolus horizontal velocities, respectively. Note that $\mathbf{F}$ is not unique since its magnitude depends on the choice of the temperature scale. This implies that $\mathbf{F}$ is only defined up to a non-divergent vector field aligned with depthintegrated horizontal flow. As discussed in the appendix, however, physically reasonable $\mathbf{F}$ fields are obtained by simply using the Celsius temperature scale.

Figure 8 illustrates that, except for near the western boundaries, the horizontal heat flux is mainly zonal. It can be noted that outside the equatorial region $\mathbf{F}$ broadly resembles the thermocline velocities shown in Fig. 1. The effects of the wind on the horizontal heat flux are most pronounced in the South Atlantic: the wind forcing essentially reverses the South Atlantic heat flux pattern, augmenting the north-westward heat flux into the Atlantic that appears to originate from the tip of Africa. Thus also in Fig. 8, a "warm-water path" circulation can be traced for the case with wind forcing.

\subsection{The potential field and stream function associated with the horizontal heat flux}

A way to further examine the patterns of the horizontal heat transport is to use the scalar potential of the divergent component of the horizontal heat flux F. Generally, the vector $\mathbf{F}$ can be written as the sum of a divergent and a non-divergent component:

$$
\mathbf{F}=\nabla \phi+\mathbf{k} \times \nabla \chi
$$

where $\phi$ and $\chi$ are scalar fields. In a steady state Eq. (2) reduces to

$$
\nabla \cdot \mathbf{F}=-Q
$$

Thus, the divergent component of $\mathbf{F}$ is uniquely determined by the Poisson equation

$$
\nabla^{2} \phi=-Q
$$


subjected to the condition that the normal component of $\nabla \phi$ vanishes on the lateral boundaries. Further, the non-divergent component is determined by the equation

$$
\nabla^{2} \chi=\mathbf{k} \cdot(\nabla \times \mathbf{F})
$$

subjected to condition that $\chi=0$ on the lateral boundaries ${ }^{1}$.

Before proceeding it is relevant to note that in the present case, where the density is a linear function of $T$ alone, the GM contribution to $\mathbf{F}$ can be simplified: using the definition of $\mathbf{v}_{*}$ and integrating by parts, one obtains

$$
\int_{-H}^{0} \mathbf{v}_{*} T d z=-K_{G M} H \nabla \bar{T}
$$

where $\bar{T}$ is the vertically-averaged temperature, which is shown in Fig. 8. Thus in the present model simulations, the depth-integrated GM horizontal heat flux is down gradient. The GM contribution to $\phi$ is hence $\phi_{G M}=-c_{p} \rho K_{G M} H \bar{T}$. This is important in the periodic channel, but tend to be smaller than the contribution from the Eulerian velocity field elsewhere.

Below computations of the functions $\phi$ and $\chi$ for the model simulations are presented. To begin with, the divergent heat flux potential $\phi$ is considered, see Fig. 9. Without wind forcing, two small but distinct ridges in the potential field prevents the heat transport from going northward in the southern Atlantic. This stands in contrast to all the cases with wind forcing, where the potential fields reveal a uniform northward transport of heat through the whole of the Atlantic. The divergent component $\phi$ of the heat flux tends to be oriented more in the meridional direction than the total horizontal heat flux F, Fig. 8, which is primarily zonally directed away from the western boundaries. This feature is most pronounced in the Atlantic. In the Indo-Pacific, the wind forcing results in a pronounced zonal gradient in $\phi$, implying a divergent heat flux directed westward. Primarily, this feature reflects the winddriven subtropical gyres, which induce a heat loss near the western boundary and a heat uptake in the interior of the basins. This gives rise to a zonal heat transport and thus a tilt in the potential lines. The easterlies also shifts the area of maximum heat uptake in the Pacific eastward, by making the thermocline more shallow and decreasing the SST near the eastern boundary.

For easy visualisation of the transport, heat streamlines were plotted from the potential field, see Fig. 10. The stream lines were computed with the NCAR Command Language (NCL), which calculate stream lines from a given velocity field. The velocity field used here

\footnotetext{
${ }^{1}$ In addition there is one part satisfying $\nabla^{2} \chi=0$, describing a non-divergent circulation around Antarctica. This component is present in Fig. 8 but will be disregarded in the computation of $\chi$.

(C) 0000 Tellus, 000, 000-000
} 
has been computed from the heat potential. Convergence zones typically cause the stream lines to eventually terminate, and divergence zones acts as starting points for the stream lines. The case with no wind has a convergence zone of heat south of the African continent, to which heat flows both from the Indo-Pacific and the Atlantic. The "realistic" wind case, on the other hand, has a clear connection between the two basins, with a transport of heat from the Indo-Pacific into the Atlantic: the top panel in Fig. 10 reveals that the heat gain in the circumpolar channel is not the only source for the heat transport to the Atlantic. Thus, the presence of wind forcing opens up a path of transport between the Indo-Pacific and the Atlantic that is responsible for a large fraction of the total heat transport. This "warm-water" path, related to the "Agulhas" dynamics (see Gordon, 1986; Döös, 1995; De Ruijter et al., 1999, and section 2.3), is not present without wind.

The stream functions $\chi$, associated with the non-divergent heat flux component, are illustrated in Fig. 11. Generally, the $\chi$ fields are characterised by clockwise/anticlockwise recirculation of heat in the northern/southern hemisphere. Thus, the $\chi$ field is dominated by a single gyre in each hemisphere. In contrast, the depth-integrated volume-flow stream function (see Fig. 5) is, in the presence of wind forcing, generally comprised by two gyres in each hemisphere: an anticyclonic subtropical gyre and a cyclonic subpolar gyre. It can be noted in Fig. 11 that even without wind there is some non-divergent heat exchange between the two basins. The wind forcing enhances this feature.

It is interesting to note that the "cold-water path" with northward heat transport into the Atlantic along the American east coast, which is seen for the case without wind in Fig. 8, is absent in the $\phi$ field, Fig. 10, but present in the $\chi$ field, Fig. 11. Thus in the case without wind, the "cold-water path" is associated with a re-circulation that does not accomplish any net heat transport into the Atlantic. The patterns of $\chi$ associated with the non-divergent heat flux also reveal the establishment of a wind-forced interbasin heat exchange in the subtropics. Further, there is no clear sign of any heat recirculation between the Circumpolar Channel and the South Atlantic. Thus, it can be concluded that despite the presence of a significant non-divergent component in the horizontal heat flux $\mathbf{F}$, the potential field $\phi$ provide useful gross information on the net interbasin heat exchange in the present case.

The heat flux potential $\phi$ has also been calculated for the the high-resolution OCCAM model, using the time-average of the surface heat fluxes for the period 1991-2002. Figure 12 shows that despite the simplicity of the two-basin model, its associated $\phi$ field is qualitatively similar to that obtained from the OCCAM model. The connection between the Atlantic and 
the Indian Ocean around the tip of Africa is evident also in the OCCAM potential field, and so is the "cold-water path" through Drake Passage. The area of maximum surface heat uptake is encountered in the tropical east Pacific, where the thermocline is the most shallow. In the Southern Ocean, the surface heat loss occurs primarily in the Indo-Pacific sector, where a convergence zone is found south of Australia. It should be underlined that possible heat re-circulation in the ACC, around Australia, and in the Indonesian Archipelago related to the non-divergent heat flux component is not captured in the potential field $\phi$. It is relevant to note that Trenberth and Solomon (1994) presented a global heat flux potential $\phi$, using a sea surface heat flux estimate calculated from top-of-the-atmosphere radiation and atmospheric reanalysis data; see their Fig. 18. The inter-basin heat exchange is less pronounced in the $\phi$ field presented by Trenberth and Solomon (1994) than in the one calculated for OCCAM in the present study.

\subsection{The meridional-temperature stream function}

To further examine the difference in the patterns of the net heat transport between the ocean basins, stream functions in the latitude-temperature plane was used (see Hirst et al., 1996; Nycander et al., 2007, for discussions of generalized stream functions). Compared to the more common overturning stream function showing streamlines in the latitude-depth plane, the ones that uses density or temperature as a generalized vertical coordinate provide more direct information on water mass transformation and heat transport (cf. Klinger et al., 2003; Nilsson et al., 2003). The stream function in the latitude-temperature plane is defined as

$$
\psi(y, T)=\int_{x_{W}}^{x_{E}} \int_{z(T)}^{0} v(x, y, z) d z d x,
$$

where $v$ is the meridional velocity with the bolus velocity from the Gent-McWilliams scheme added and $z(T)$ the depth to a certain isotherm $T$. As defined here, $-\frac{\partial \psi(y, T)}{\partial T} d T$ is the northward volume transport in the temperature interval from $T$ to $T+d T$. The corresponding contribution to the meridional heat transport is $-\rho c_{p} T \frac{\partial \psi(y, T)}{\partial T} d T$ : By integrating this expression over temperature one finds after some manipulations that

$$
H(y)=\rho c_{p} \int_{T_{\min }}^{T_{\max }} \psi(y, T) d T .
$$

Thus, the meridional heat transport is obtained by integrating $\psi(y, T)$ over all temperatures, showing the close relation between the temperature-latitude stream function and the heat (C) 0000 Tellus, 000, 000-000 
transport. It should be noted that Eq. (10) also can be used to calculate the heat transport contribution from a certain temperature interval for which $\psi\left(y, T_{\min }\right)=0$ and $\psi\left(y, T_{\max }\right)=$ 0 ; an example is given below.

Figure 13 shows $\psi(y, T)$ for the Atlantic and the Indo-Pacific basins together with the Southern Ocean. In the South Atlantic, $\psi(y, T)$ is comprised of two cells ${ }^{2}$ : One warmer clockwise cell, exporting warm near surface water, and one colder anticlockwise cell, exporting cold deep water. Both cells have a compensating import of water with intermediate temperatures. Without wind forcing, the warmer cell is bounded by the $3^{\circ} \mathrm{C}$ isotherm, which reaches a maximum depth of about $300 \mathrm{~m}$. With wind forcing, this cell is encountered for depths shallower than about $100 \mathrm{~m}$. From Eq. (10) it follows that the warmer cell transports heat southwards, whereas the colder cell transports heat northward. Thus, the two cells compete in setting the direction of the South Atlantic heat transport. In the absence of wind forcing, the transports of the warm and the cold cells are -56 TW and 17 TW, respectively; yielding a net southward heat transport of $-38 \mathrm{TW}$. In the presence of wind forcing, the corresponding numbers are -6 TW and 98 TW, respectively; yielding a net northward heat transport of 94 TW. Accordingly, the wind forcing reduces the southward heat transport of the warmer cell, simultaneously as it enhances the northward heat transport of the colder cell. This is associated with an increase of the Atlantic deep water export, which is about $2 \mathrm{~Sv}$ without wind forcing and about $5 \mathrm{~Sv}$ with. Figure 13 reveals that a similar two-cell overturning structure, with oppositely directed heat transports, is also found in the North Indo-Pacific.

One important effect of the wind forcing is to raise the maximum temperature of the Atlantic inflow from about 3 to $10{ }^{\circ} \mathrm{C}$. The relatively high inflow temperatures reveal an Indo-Pacific origin: Although there is some surface heat gain over the Southern Ocean, forced essentially by the northward surface Ekman drift, this heat gain occurs for temperatures below $6^{\circ} \mathrm{C}$; and heat loss occurs for all higher temperatures. This shows that in the present model, the heat export from the Indo-Pacific accounts for a large part of the heat transport into the Atlantic.

In the Indo-Pacific, the import of deep water colder than about $1^{\circ} \mathrm{C}$ is about $6 \mathrm{~Sv}$ without wind forcing. In the presence of wind forcing, the deep water import is reduced to $4 \mathrm{~Sv}$. It

\footnotetext{
2 For temperatures below about $0.2^{\circ} \mathrm{C}$, there is also a bottom water cell with inflow of deep water from the circumpolar channel and outflow of slightly warmer Atlantic deep water. Its strength, which is rather insensitive to the wind forcing, is about 2 Sv; this cell is poorly resolved in Fig. 13. However, its contribution to the Atlantic heat transport is negligible.
} 
should be noted that the change of the GM bolus velocities accounts for the main decrease of the deep water import. Similar but smaller wind-induced decreases of the Indo-Pacific deep water import were seen in the Eulerian latitude-depth stream function in the idealised two-basin simulations of McDermott (1996) and Hirabara et al. (2007). As can be seen in Fig. 13, however, the wind forcing augments the export of warm near-surface water, which results in an essentially unaltered heat export, despite the reduction of the deep water inflow.

The Southern Ocean is, without wind forcing, dominated by a single clockwise cell, with near surface water flowing southward, being cooled and returning northward. In the Circumpolar Channel the GM bolus velocity dominates $\psi(y, T)$. A large amount of water with a temperature just above $0^{\circ} \mathrm{C}$ enters into the Indo-Pacific, while the Atlantic is receiving slightly warmer water. In the presence of wind forcing, a three cell structure emerges. (This feature is more pronounced for the case with 2 times the normal wind amplitude, not shown). There are now clockwise flowing surface and bottom water cells, transporting heat southwards, as well as a weak anticlockwise cell, transporting heat northwards (see e.g. Marshall and Radko, 2006; Döös et al., 2008, for discussions of the real Southern Ocean). This latter cell is associated with heating and upwelling of deep water originating from the North Atlantic. It should be noted that for moderate-to-strong wind forcing there is a large degree of cancelation in the Southern Ocean between the GM bolus velocity field, inducing a southward heat flux, and the Eulerian velocity field, inducing primarily a northward heat transport, resulting in a relatively weak $\psi(y, T)$. The water leaving the Southern Ocean has now temperatures reaching about $9^{\circ} \mathrm{C}$, which is significantly warmer than in the case without wind forcing.

The meridional-temperature stream function has also been calculated with the OCCAM fields and is presented in Fig. 14. The figure shows the average of all stream functions produced for the 5 days fields from 1991-2002. A comparison shows that several qualitative features seen in the $\psi(y, T)$ stream function from the idealised model are present also in the results from OCCAM. The common presence of the two-cell structure in the South Atlantic and North Indo-Pacific and the three-cell structure in the Southern Ocean are noteworthy. The OCCAM results show, however, some additional detailed features such as the deep Antarctic Bottom Water cell, which exports cold water from the Southern Ocean where it is weakly heated and returns back a few degrees warmer water. The idealised model tends instead to connect this cell into the tropical cell in the Indo-Pacific.

(c) 0000 Tellus, 000, 000-000 


\section{Sensitivity Analysis}

The results of this study indicates that the wind stress, in particular over the Southern Ocean, affects the inter-basin heat exchange. Previous studies, however, have shown that the sensitivity of the Atlantic meridional overturning circulation to wind forcing depends on the surface boundary conditions of temperature and salinity: the circulation reacts more strongly to Southern Ocean wind forcing under restoring surface boundary conditions than under mixed or flux boundary conditions (cf. Rahmstorf and England, 1997; Bugnion et al., 2006). Rahmstorf and England (1997) argued that the reason is a negative feedback between the strength of the Atlantic overturning circulation and the inter-hemispheric difference in highlatitude surface density associated with the flow. Strong restoring of the surface density acts to suppress this negative feedback. The present model has restoring boundary conditions, a fact that should be kept in mind when interpreting the results of the sensitivity analysis presented below; this issue is discussed briefly from a coupled ocean-atmosphere perspective in the final section.

\subsection{The pattern of wind-induced heat flux anomalies}

Previous studies have shown that wind forcing in the northern hemisphere may have a quite different impact on the circulation and the heat transport than wind forcing in the southern hemisphere, an issue that has been examined in some detail in single twohemisphere basins (Tsujino and Suginohara, 1999; Klinger et al., 2003; 2004). In a geometry of this kind an equatorially-symmetric wind forcing tends to amplify pre-existing interhemispheric asymmetries of the flow, caused by asymmetries in the surface density field and/or the presence of a circumpolar channel. In particular, a westerly mid-latitude wind anomaly creates a stronger cross-equatorial response when it is applied in the hemisphere containing the circumpolar channel or the less dense high-latitude surface water (Klinger et al., 2004).

The present simulations are conducted in a two-basin geometry that have a circumpolar channel and inter-hemispheric as well as inter-basin differences in surface density. Accordingly, changes of the wind in the northern and southern hemisphere may have different impacts on the flow and the heat transport. To examine this issue, three wind-anomaly cases have been constructed:

(i) The anomaly response to a doubling of the wind stress south of $30^{\circ} \mathrm{S}$, implying a 
strengthening of westerlies in the Southern Hemisphere, defined as the difference between the "realistic" and the "symmetric" wind cases; see Fig. 2.

(ii) The anomaly response to a doubling of the wind stress north of $30^{\circ} \mathrm{S}$, implying a strengthening of westerlies in the Northern Hemisphere as well as the easterlies in both hemispheres, defined as the difference between the "symmetric" and the $0.5 x$ "realistic" wind cases.

(iii) The anomaly response to a doubling of the entire symmetric wind stress field, defined as the difference between the "symmetric" and the $0.5 x$ "symmetric" wind cases.

Note that the sum of the wind anomalies of the first two cases equals the doubling anomaly of the symmetric wind field in case (iii). However, as will be seen the heat-transport response is not linear.

Figure 15 shows the resulting anomalies in meridional heat transports and the heat potential fields. Additional information can be found in Fig. 16 showing the meridional heat transport for the three different wind cases at normal wind strength, and no wind. Consider to begin with the effect of strengthening the westerlies in the Southern Hemisphere, Fig.15 $\mathrm{a}$ and $\mathrm{b}$. This wind change induces a northward heat transport anomaly at all latitudes and in all basins. Klinger et al. (2003) obtained a similar result in a single basin experiment, and Hasumi and Suginohara (1999) in a global model. The northward transport anomaly in the Atlantic is roughly a factor of three greater than that in the Indo-Pacific, which is also visible in the pattern of the heat potential anomaly. This result is also seen in Fig. 16, where the "realistic" wind case and the "symmetric" wind case gives similar response over the Indo-Pacific, even though the wind forcing over the Southern Ocean is twice as strong in the "realistic" case. An inspection of the other wind-forcing strengths (not shown) confirms that as long as the wind forcing north of $30^{\circ} \mathrm{S}$ is the same then the poleward heat transport in Indo-Pacific will be about the same as well.

For a fixed geometry, the partitioning of the northward transport anomaly between the two basins should be chiefly controlled by the inter-basin difference in high northern latitude surface densities; for results on how the inter-basin density difference affects the overturning responses to wind changes see Hirabara et al. (2007). An inspection of the response in $\psi(y, T)$ (not shown) reveals that the wind increase over the Southern Ocean increases the Atlantic deep water export with about $2 \mathrm{~Sv}$, whereas it decreases the Pacific deep water import with about $1 \mathrm{~Sv}$. Note that the northward heat transport anomaly in the Southern Ocean, seen (C) 0000 Tellus, 000, 000-000 
in Fig. 15 a, does not indicate northward transports of heat in the reference simulations; see Fig. 16. Rather, it reflects a wind-induced decrease of a southward heat transports between the two simulations. Thus, the northward heat transport anomaly is primarily associated with a strengthening of the heat transport from the Indo-Pacific to the Atlantic, an effect that reduces the poleward heat transport in the Southern Ocean.

When the trade winds and the Northern Hemisphere westerlies are increased, Fig. 15 c and $\mathrm{d}$, the enhancement of poleward transport in the tropical cells tend to dominate the anomaly response; a pronounced heat-gain anomaly is created near the equator. However, the heat export from the Indo-Pacific exhibits a stronger response in this case than that of the Atlantic (Fig. 15 c ). A closer inspection reveals that the southward heat transport anomaly in the Indo-Pacific has roughly the same amplitude at the equator as at the southern basin border. Thus, this cross-equatorial anomaly may be created by an enhanced surface heat uptake in the zone of northern-hemisphere westerlies in the fashion outlined by Klinger et al. (2004). Note further that a northward heat anomaly is induced in the Southern Ocean, outside the region of wind change. (Although this remotely-forced response is interesting, it was found that its structure varies significantly with the base-line wind forcing used for constructing the anomaly. This issue is not pursued further.)

Also when the entire wind field is enhanced, the response of the tropical cells strongly shape the anomaly pattern, Fig. 15 e and f. In the Atlantic the heat transport anomaly is again directed northward: there is an additional $0.02 \mathrm{PW}$ northward transport at all latitudes reflecting an increase in heat import. The response in the Indo-Pacific is weaker, which can be explained by the nearly compensating heat-export anomalies produced for the anomaly cases 1 and 2. Accordingly, a global wind increase entails two counteracting responses in the Indo-Pacific: the Southern Hemisphere westerlies force a northward transport anomaly whereas the ones in the Northern Hemisphere force a southward transport anomaly. It should be noted, however, that the anomaly cases considered here are not linear: The heat export anomaly from the Indo-Pacific in case (iii) is not equal to the sum of the heat export anomalies from case (i) and (ii), although the resulting wind anomalies are identical. Thus, the response to the wind-forcing anomaly depends on the reference wind field and hence the background-state circulation.

The heat flux potential anomalies reveal two-dimensional aspects of the heat transports response. The westerlies in the southern hemisphere exerts a main control of the heat transport anomaly into the Atlantic. The doubling of the symmetric wind field produces a $\phi$ 
anomaly in case (iii) that has similarities with that of case (i), where the Southern Hemisphere westerlies were doubled. In the Indo-Pacific, on the other hand, the winds in the Northern Hemisphere dominates the $\phi$ response, and the pattern in anomaly case (iii) resembles case (ii), where the northern winds were doubled.

\section{$5 \quad$ Discussion and general conclusions}

We have examined the pathways of the horizontal heat transport in the Southern Ocean and between the Atlantic and the Indo-Pacific basins in a series of idealised numerical experiments, and how these pathways are influenced by the wind forcing. The present results, summarised in Figs. 8-11, show that the presence of wind alters the origin of the heat that flows into the Atlantic by establishing a "warm-water path" heat-transport connection between the Atlantic and the Indo-Pacific around the tip of Africa. Without wind forcing the heat transport follows a "cold-water path", entering the Atlantic from the circumpolar Channel along the east coast of America; however, southward heat transport outside the western boundary current results in a net heat export from the Atlantic.

Our interpretation of the heat-transport response to the global wind forcing in the idealised two-basin model can be summarised as follows: The winds reduce the surface heat loss in the Southern Ocean but have little influence on the heat transport out of the Indo-Pacific, which is determined primarily by the downward heat flux created by the vertical mixing in the thermocline within the basin (Munk and Wunsch, 1998; Scott and Marotzke, 2002). As a consequence, a compensating amount of the heat export from the Indo-Pacific must enter

the Atlantic, where the surface heat loss in the northern hemisphere is increased; see Fig. 9. An important feature is that the equatorward surface Ekman transport in the circumpolar channel initially serves to diminish a net poleward surface transport accomplished by baroclinic eddies (Marshall and Radko, 2006), here represented by the GM scheme, which is associated with a net sinking. Thus, there is a minimum wind forcing required for creating net upwelling and surface heat gain in the Southern Ocean; a feature suggested by the scaling arguments due to Klinger et al. (2004). Below this forcing strength, the winds over the Southern Ocean primarily act to re-route the heat export from the Indo-Pacific into the Atlantic.

Further, in the idealised two-basin, the effect of the wind forcing on the meridional heat transport in the Southern Ocean tends to be stronger north of Cape Horn than in the (C) 0000 Tellus, 000, 000-000 
Drake Passage; Fig. 7 shows that the impact of the wind is rather small in the circumpolar channel. In fact, the Southern Ocean winds north of the circumpolar channel tend to be more important for the Atlantic heat transport. Using a single-basin model,Klinger et al. (2003) also found that wind forcing equatorward of rather than over the circumpolar channel had the greatest impact of the remote heat flux response. This feature is difficult to explain on the basis of the "Drake Passage" effect as it was originally formulated by Toggweiler and Samuels (1995). In the idealized two-basin model, the significance of the winds equtorward of the circumpolar channel are presumably associated with the wind-driven Sverdrup circulation north of Cape Horn, which near the tip of Africa acts to drive the out-flowing Indo-Pacific thermocline water westward into the Atlantic (see e.g. De Ruijter et al., 1999; LaCasce and Isachsen, 2007). Such a wind routing is broadly consistent with the adjoint sensitivities to wind forcing of the North Atlantic meridional overturning circulation computed by Bugnion et al. (2006): They found that the sinking in the North Atlantic was most sensitive to the wind forcing near the south tip of Africa.

It should be noted that, in the present two-basin model, a wind increase over the Southern Ocean yields a remote heat transport response in the Atlantic as well as the Indo-Pacific, although the amplitude is smaller there; see Fig. 15. We have not been able to formulate a conceptual model that explains this partitioning and more fundamentally provides a mechanistic link between the wind forcing and the interbasin heat transport. Obviously, such a conceptual model must include two basins. However, most attempts to re-interpret the mechanisms underlying the impact of Southern Ocean winds on the Atlantic meridional overturning, which Toggweiler and Samuels (1995) identified, have been based on a single basin "Atlantic only" perspective. This have been done either explicitly as in the single-basin studies of Tsujino and Suginohara (1999) and Klinger et al. (2003; 2004) or in an implicit manner such as in the studies of Rahmstorf and England (1997) and Gnanadesikan (1999), which to some extent assume a dynamically passive Indo-Pacific.

As pointed out by Rahmstorf and England (1997) and Bugnion et al. (2006) the surface boundary conditions on temperature and salinity determine the degree to which the winds over the Southern Ocean can affect the meridional overturning in the North Atlantic: the weakest wind influence is obtained for weaker restoring or a flux boundary condition for the surface temperature. A flux boundary condition for the temperature in the present model would prescribe the horizontal heat transport, making it independent of the wind forcing as well as of parameters such as the vertical diffusivity. However, changes in the strength of the 
global surface wind field should be associated with changes of the surface heat flux over the ocean, a feature that the present restoring surface boundary conditions reflect. Thus, the relevant question is whether the wind-induced changes of the surface heat flux in the present ocean-only model are qualitatively consistent with those that would result in a fully-coupled model; if e.g. somehow the high-latitude southern hemisphere winds were intensified. One fundamental constraint is that the combined poleward heat transport in the ocean and the atmosphere should remain nearly fixed provided that the solar forcing and the planetary albedo are constant (Stone, 1978; Enderton and Marshall, 2008). Accordingly, if stronger surface winds are associated with enhanced atmospheric heat transport, then a wind-induced reduction of the poleward heat transport in the Southern Ocean is qualitatively in accordance with the constancy of the combined poleward heat transport proposed by Stone (1978). However, the fairly strong restoring of the sea surface temperature and the omission of the surface freshwater flux and the effect of the salinity on the circulation presumably make the heat transport in the present model rather sensitive to surface wind changes. Nevertheless, the present simulations should illuminate qualitatively how the winds act to reorganise and modify the heat transport pattern that is created by the small-scale vertical mixing in the absence of wind forcing.

In the examination of the interbasin heat transport the scalar potential $\phi$ of the divergent component of the horizontal heat flux proved illuminating. One advantage of $\phi$ is that it represents a "coarse-grained" image of the surface heat flux, capturing the large-scale features of the horizontal heat transport. Another advantage is that in a steady state $\phi$ can be computed from a knowledge of the surface heat flux alone, i.e. no information of the three-dimensional temperature and velocity fields are required. In contrast, vector plots of the horizontal heat flux vector (see Eq. (3) and Fig. 8) tend to be dominated by intense transport in the western boundary currents, making it more difficult to discern the interbasin heat exchange. In addition, there is the problem of specifying a unique horizontal heat flux vector (see the appendix). The same uniqueness problem applies for $\chi$, the stream function for the rotational component of the horizontal heat flux vector. Thus as a complement to the overturning stream functions and the meridional heat transport, we argue that $\phi$ is a valuable diagnostic tool for analysing the large-scale circulation and we hope the present work will inspire other researchers to use and analyse the scalar potential $\phi$.

A final comment on the limitations of the highly idealised nature of the present twobasin model is relevant. In reality as well as in the present model, the Agulhas region plays (c) 0000 Tellus, 000, 000-000 
a critical role for the interbasin exchange of water masses and heat. The coarse resolution and extremely simplified bathymetry of the present model fail to capture important aspects of the dynamics in this region (De Ruijter et al., 1999; Dijkstra and De Ruijter, 2001). In addition, as shown by Bugnion et al. (2006) the details of the wind forcing here may be important for the strength of the meridional overturning in the Atlantic. Evidently, the present model results should provide only qualitative information of how the surface winds affect the heat transport into the Atlantic. However, the fact that the scalar potential $\phi$ of the idealised model (Fig. 10) reproduces the gross features of that calculated from the high resolution model OCCAM (Fig. 12) suggests that the present two-basin model indeed serves as crude qualitative analogue of the ocean circulation.

\section{Acknowledgements}

The work reported here was supported by the Swedish Research Council and is a contribution from the Bert Bolin Climate Research Centre at Stockholm University. We thank Jeff Scott and an anonymous reviewer for their constructive suggestions for improving our original manuscript. We also thank Andrew Coward and the OCCAM team for providing their model simulations.

\section{Appendix}

In section 3.2, it was noted that $\mathbf{F}$, the horizontal heat flux vector defined by Eq. (3), is not unique since its magnitude depends on the choice of the temperature scale. To illustrate some of the problems that can arise from this ambiguity, we rewrite $\mathbf{F}$ as follows: We denote the vertically-averaged temperature $\bar{T}$ and the anomaly $T^{\prime}$ and decompose the horizontal velocity field in the same way. By using this in Eq. (3), we arrive after some calculations at

$$
\mathbf{F}=c_{p} \rho \bar{T} \mathbf{k} \times \nabla \Psi+c_{p} \rho \int_{-H}^{0}\left(\mathbf{v}^{\prime}+\mathbf{v}_{*}^{\prime}\right) T^{\prime} d z .
$$

Here $\Psi$ is the depth-integrated Eulerian stream function, defined through $\int_{-H}^{0} \mathbf{v} d z=\mathbf{k} \times \nabla \Psi$; note that $\int_{-H}^{0} \mathbf{v}_{*} d z=0$. In Eq. (11), the first term on the right-hand side depends on the choice of the temperature scale, whereas the second does not. For instance, if one uses the Kelvin temperature scale, then $\mathbf{F}$ will be completely dominated by first term and hence aligned with the barotropic flow.

To address this problem, we note that the transformation $T \rightarrow T+T_{0}$ implies that 
$\mathbf{F} \rightarrow \mathbf{F}+c_{p} \rho T_{0} \mathbf{k} \times \nabla \Psi$, where $T_{0}$ is an arbitrary constant temperature. Accordingly, $\mathbf{F}$ is only defined up to a non-divergent vector field aligned with depth-integrated horizontal flow. Our aim is to specify $c_{p} \rho T_{0} \mathbf{k} \times \nabla \Psi$ such that a specific horizontal heat flux vector

$$
\mathbf{F}_{s}=\mathbf{F}+c_{p} \rho T_{0} \mathbf{k} \times \nabla \Psi,
$$

has reasonable physical features. Analogous problems of non-uniqueness of rotational vector fields have been discussed by Boccaletti et al. (2005), in the context of the ocean heat flux in the meridional-vertical plane, and by Marshall et al. (2001), in the context of the oceanic potential vorticity flux.

In the example of the Kelvin scale, mentioned above, it is a rotational component of $\mathbf{F}$ that becomes very large. Thus, one reasonable way of selecting $\mathbf{F}_{s}$ is to determine the arbitrary constant $T_{0}$ such that the rotational component of $\mathbf{F}_{s}$ is minimised in a least-square sense. This can be done by minimising the integral $\iint_{A}\left|\nabla \times \mathbf{F}_{s}\right|^{2} d A$. Straightforward manipulations show that for this choice

$$
T_{0}=-\frac{\iint_{A} \mathbf{k} \cdot(\nabla \times \mathbf{F}) \nabla^{2} \Psi d A}{c_{p} \rho \iint_{A}\left(\nabla^{2} \Psi\right)^{2} d A},
$$

where $A$ is the entire domain. Another choice is to minimise the squared heat flux, i.e. the integral $\iint_{A}\left|\mathbf{F}_{s}\right|^{2} d A$. Straightforward manipulations yield in this case

$$
T_{0}=-\frac{\iint_{A} \mathbf{F} \cdot(\mathbf{k} \times \nabla \Psi) d A}{c_{p} \rho \iint_{A}|\nabla \Psi|^{2} d A} .
$$

In Fig. 8 the horizontal heat flux is calculated using $T_{0}$ as defined in Eq. (13). For the cases with no wind and realistic wind, we obtain $T_{0}=0.25{ }^{\circ} \mathrm{C}$ and $T_{0}=-0.99{ }^{\circ} \mathrm{C}$, respectively. The corresponding $\mathbf{F}_{s}$ fields with $T_{0}$ defined by Eq. (14) (not shown) are highly similar; with $T_{0}=-1.07{ }^{\circ} \mathrm{C}$ and $T_{0}=-0.92{ }^{\circ} \mathrm{C}$ for the case without and with wind, respectively. Note that without wind forcing, the barotropic stream function $\Psi$ is so small outside the periodic channel that the difference in $T_{0}$ is essentially insignificant for the resulting $\mathbf{F}_{s}$. The $\mathbf{F}_{s}$ fields obtained by setting $T_{0}=0$ (not shown) differ qualitatively from the ones shown in Fig. 8 only in the high southern latitudes, where the negative $T_{0}$ values cause a westward heat flux near 50 degrees south. Thus, outside the periodic channel the arbitrary component $c_{p} \rho T_{0} \mathbf{k} \times \nabla \Psi$ has only a small influence on the heat flux pattern, provided that $T_{0}$ is on the same order as the volume-mean temperature. Note that Fig. 11, showing the heat flux stream functions, have been calculated using $\mathbf{F}_{s}$ specified by Eq. (13). 


\section{REFERENCES}

Blanke, B., Speich, S., Madec, G. and Döös, K. 2001. A Global Diagnostic of Interocean Mass Transfers. J. Phys. Oceanogr. 31:6, 1623-1642.

Boccaletti, G., Ferrari, R. , Adcroft, A., Ferreira, D. and Marshall, J. 2005. The vertical structure of ocean heat transport. Geophys. Res. Lett. 32, L10603.

Bugnion, V., Hill, C.and Stone, P.H. 2006. An Adjoint Analysis of the Meridional Overturning Circulation in a Hybrid Coupled Model. J. Climate 19, 3751-3767.

Coward, A. C. and de Cuevas, B. A. 2005. The OCCAM 66 Level Model: physics, initial conditions and external forcing. SOC Int. Rep. 99, National Oceanogr. Cent., Southampton, UK.

De Boer, A.M., Toggweiler, J.R.and Sigman, D.M. 2008. Atlantic dominance of the meridional overturning circulation. J. Phys. Oceanogr. 38, 435-450.

De Ruijter, W.P.M, Biastoch, A, Drijfhout, S.S., Lutjeharms, J.R.E, Matano, R.P., Pichevin, T., van Leeuwen, P.J. and Weijer, W.1999. Indian-Atlantic interocean exchange: Dynamics, estimation and impact. J. Geophys. Res. 104, 20885-20910.

Dijkstra, H.A. and De Ruijter, W.P.M 2001. On the physics of the Agulhas Current: Steady retroflection regimes. J. Phys. Oceanogr. 31, 2971-2985.

Döös, K. and Webb, D.J. 1994. The Deacon cell and other meridional cells in the Southern Ocean. J. Phys. Oceanogr. 24, $429-442$.

Döös, K. 1995. Inter-ocean exchange of water masses. J. Geophys. Res. 100(C7), 13499-13514.

Döös, K. and Coward, A.C. 1997. The Southern Ocean as the major upwelling zone of the North Atlantic Deep Water. WOCE Newsletter. No.27, July 1997, 3-17.

Döös, K., Nycander, J. and Coward, A.C. 2008. Lagrangian decomposition of the Deacon Cell. J. Geophys. Res. 113, C07028, doi:10.1029/2007JC004351..

Enderton, D. and Marshall, J. 2008. Explorations of atmosphere-ocean-ice climates on an aqua-planet and their meridional energy transports. J. of the Atmos. Sci. DOI: 10.1175/2008JAS2680.1

Fox, A. D., Haines, K. , de Cuevas, B.A. and Webb, D. J. 2000. Altimeter assimilation in the OCCAM global model: Part I: A twin experiment. J. Mar. Systems 26, 303-322.

Gent, P. R. and McWilliams, J. C. 1990. Isopycnal mixing in ocean circulation models. J. Phys. Oceanogr. 20, 150-155.

Gordon, A. L. 1986. Interocean Exchange of Thermocline Water. J. Geophysical Res. 91(C4), 5037-5046.

Hasumi, H. and Suginohara, N. 1999. Atlantic deep circulation controlled by heating in the Southern Ocean. Geophys. Res. Lett.. 26:13, 1873-1876.

Held, I. M. 2001. The partitioning of the poleward energy transport between the tropical ocean and atmosphere. J. Atmos. Sci. 58, 943-948.

Hellerman, S. and Rosenstein, M. 1983. Normal monthly wind stress over the world ocean with error estimates. J. Phys. Oceanogr. 13, 1093-1104.

Hirabara, M., Ishizaki, H. and Ishikawa, I. 2007. Effect of the westerly wind stress over the Southern Ocean on the meridional overturning. J. Phys. Oceanogr. 37, 2114-2132.

Hirst, A. C, Jackett, D. R. and McDougall, T. J 1996. The meridional overturning cells of a world ocean model in neutral coordinates. J. Phys. Oceanogr. 26, 775-791.

Hughes, T. M. C. and Weaver, A. J. 1994. Multiple Equilibria of an Asymmetric Two-Basin Ocean Model. J. Phys. Oceanogr. 24, 619-637.

Gnanadesikan, A 1994. A simple predictive model for the structure of the oceanic pycnocline. Science 283, 2077-2079.

Klinger, B. A. and Marotzke, J. 2000. Meridional Heat Transport by the Subtropical Cell. J. Phys. Oceanogr. 30, 696-705.

Klinger, B. A., Drijfhout, S., Marotzke, J. and Scott, J. R. 2003. Sensitivity of Basinwide Meridional Overturning to Diapycnal Diffusion and Remote Wind Forcing in an Idealized Atlantic-Southern Ocean Geometry. J. Phys. Oceanogr. 33, $249-266$. Klinger, B. A., Drijfhout, S., Marotzke, J. and Scott, J. R. 2004. Remote Wind-Driven Overturning in the Absence of the Drake 
Passage Effect. J. Phys. Oceanogr. 34, 1036-1049.

Kuhlbrodt, T., Griesel, A., Montoya, M., Levermann, A., Hofmann, M. and Rahmstorf, S. 2007. On driving processes of the Atlantic meridional overturning circulation. Rev. Geophys. 45, doi:10.1029/2004RG000166.

LaCasce, J. H. and Isachsen, P. E. 2007. On Sverdrup discontinuities and vortices in the southwest Indian Ocean. J. Phys. Oceanogr. 37, 2940-2950.

Large, W.G., Danabasoglu, G. and Doney, S.C. 1997. Sensitivity to surface forcing and boundary layer mixing in a global ocean model: annual-mean climatology. J. Phys. Oceanogr. 27, 2418-2446.

Levitus, S., Gelfeld, R. D., Boyer, T. and Johnson, D.. 1994. Results of the NODC and IOC Data Archaeology and Rescue Projects. Key to Oceanographic Records Documentation No. 19 National Oceanographic Data Center, Washington, DC

Marsh, R., Josey, S.A., Nurser, A.J.G., de Cuevas, B.A. and Coward, A. C. 2005a. Water mass transformation in the North Atlantic over 1985-2002 simulated in an eddy-permitting model. Ocean Science. 1, 127-144.

Marsh, R., de Cuevas, B. A., Coward, A. C., Bryden, H. L. and Alvarez M. 2005b. Thermohaline circulation at three key sections in the North Atlantic over 1985-2002. Geophys. Res. Lett. 32, L10604, doi:10.1029/2004GL022281.

Marshall, J., Adcroft, A., Hill, C., Perelman, L., and Heisey, C. 1997. A finite-volume, incompressible Navier Stokes model for studies of the ocean on parallel computers. J. Geophysical Res. 102(C3), 5753- 5766.

Marshall, J., Jamous, D. and Nilsson, J. 2001. Entry, flux, and exit of potential vorticity in ocean circulation. J. Phys. Oceanogr. 31, 777-789.

Marshall, J. and Radko, T. 2006. A model of the upper branch of the meridional overturning of the southern ocean. Prog. in Oceanogr. 70, 331-345.

Matano, R.P. 1996. A numerical study of the Agulhas retroflection: The role of bottom topography. J. Phys. Oceanogr. 26, $2267-2301$.

McDermott, D. A. 1996. The Regulation of Northern Overtuning by Southern Hemisphere Winds. J. Phys. Oceanogr. 26, $1234-1255$.

Munk, W. and Wunsch, C. 1998. Abyssal recipes II: energetics of tidal and wind mixing. Deep-Sea Res. 45, 1977-2010.

Nilsson, J., Broström, G., and Wallin, G. 2003. The thermohaline circulation and vertical mixing: does weaker density stratification give stronger overturning?. J. Phys. Oceanogr. 33, 2781-2795.

Nøst, O.-A., Nilsson, J. and Nycander, J. 2008. On the asymmetry between cyclonic and anticyclonic flow in basins with sloping boundaries. J. Phys. Oceanogr. 38, 771-787.

Nycander, J., Nilsson, J., Döös, K. and Broström, G. 2007. Thermodynamic analysis of ocean circulation. J. Phys. Oceanogr. 37, 2038-2052.

Rahmstorf, S. and England, M. H. 1997. Influence of Southern Hemisphere Winds on North Atlantic Deep Water Flow. J. Phys. Oceanogr. 27, 2040-2054.

Scott, J. R., and Marotzke, J. 2002. The location of diapycnal mixing and the meridional overturning circulation. J. Phys. Oceanogr. 32, 3578-3595.

Stone, P.H. 1978. Constraints on dynamical transports of energy on a spherical planet. Dynamics of Atmospheres and Oceans. 2:2, 123-139.

Toggweiler, J. R. and Samuels, B. 1995. Effect of Drake Passage on the global thermohaline circulation. Deep-Sea Reas. textbf42:4, 477-500.

Toggweiler, J. R. and Samuels, B. 1998. On the oceanss large scale circulation near the limit of o vertical mixing. J. Phys. Oceanogr. 28, 1832-1852.

Trenberth, K. E. and Solomon, A. 1995. The global heat balance: heat transport in the atmosphere and ocean. Climate Dyn. 10, 107-134.

Tsujino, H. and Suginohara, N. 1999. Thermohaline Circulation Enhanced by Wind Forcing. J. Phys. Oceanogr. 29, $1506-1516$. 
Figure 1: Temperature, in gray scale, and velocity vectors, at 300 meters depth for the realistic wind profile case and the case with no wind. In the idealized model, the narrow and wide basins are referred to as the "Atlantic and the "Pacific", respectively. The north-south land barrier extending furthest southward is "America"; the other one is "Africa", which 'tip" is located roughly at $20^{\circ}$ south.

Figure 2: Left panel: Zonal component of the wind stress in $N / \mathrm{m}^{2}$, as a function of latitude. The three cases are; a wind profile with realistic proportions from climatology by Hellerman and Rosenstien (1983) denoted "realistic" wind, symmetric wind and only wind over the Southern Ocean. The two stars indicates the positions of the end of Drake passage and the tip of the "African" continent. Right panel: the Ekman transport in Sverdrups for the three wind cases.

Figure 3: The meridional overturning stream function for the "realistic" wind case, for the entire ocean (top), the Atlantic Ocean (middle) and the Indo-Pacific Ocean (bottom). The flow between the streamlines is in Sverdrups.

Figure 4: The meridional overturning stream function for the case with no wind. The entire ocean (top), the Atlantic Ocean (middle) and the Indo-Pacific Ocean (bottom). The flow between the streamlines is in Sverdrups.

Figure 5: The barotropic stream function (panel a), in units of Sverdrup, and the sea surface height (panel b), in units of meter, for the "realistic" wind case. In a) positive values implies counter clockwise flow and the zero contours are indicated with white lines. To highlight "Agulhas" retroflection, the 0.2 meter contour is indicated with a black line in panel b.

Figure 6: The meridional overturning stream function simulated by OCCAM. The figure shows the average of all stream functions calculated for the 5 days fields from 1991-2002. The transport between the streamlines is in Sverdrups.

Figure 7: Net northward heat transport in PW $\left(10^{15} \mathrm{~W}\right)$. The left panel shows the total transport for the whole model ocean in the realistic wind case compared to the case with no wind. The right panel shows the same cases but divided into the sub-basins.

Figure 8: The horizontal heat flux F, as defined by Eq. (3), (vectors) and the verticallyaveraged temperature in ${ }^{\circ} \mathrm{C}$ (gray scale) for the cases with realistic wind and no wind. Some details in the computation of $\mathbf{F}$ are discussed in the appendix.

Figure 9: The divergent heat potential fields $\phi$ for the reference case with no wind, and the three different wind cases, in PW $\left(10^{15} \mathrm{~W}\right)$. It is $0.025 \mathrm{PW}$ between the white lines. To keep the same colour scale between the figures of the different wind cases some of the features of 
the "no wind"-case is lost. To enhance the pattern in the South Atlantic some additional potential lines have been added in panel (a). They are shown in black, and are 5 TW $\left(10^{12}\right.$ W) apart.

Figure 10: Heat streamlines plotted in the heat potential fields for the the case with realistic wind, and the reference case with no wind. The potential fields are the same as in the top panels in Fig. 9.

Figure 11: The non-divergent horizontal heat flux streamfunction $\chi$ in PW $\left(10^{15} \mathrm{~W}\right)$; see Eqs. $(4,7)$ and the text for details. Negative/positive values indicate clockwise/anticlockwise flow direction, 0.05 PW between the contour lines.

Figure 12: Heat streamlines plotted in the heat potential field from the OCCAM model, for the year 1992 .

Figure 13: Temperature-latitude stream functions for the case with realistic wind (top) and the reference case with no wind (bottom). The panels to the left show the Atlantic and the Southern Ocean and, the right panels show the Indo-Pacific and the same plots of the Southern Ocean. The color scale displays the flow in Sverdups, and it is $0.5 \mathrm{~Sv}$ between the stream lines.

Figure 14: Temperature-latitude stream functions for the OCCAM model. The figure shows the average of all stream functions calculated for the 5 days fields from 1991-2002. It is 4 Sverdrups between the stream lines.

Figure 15: Anomalies in the meridional heat transport, in $10^{14} \mathrm{~W}$, and the heat potential fields, with $0.1 * 10^{14} \mathrm{~W}$ between the potential lines. For the meridional heat transport, the solid, dashed, and dashed-dotted lines represent the total, Atlantic and Indo-Pacific anomalies, respectively. The top panels are the anomalies for a doubling of the wind south of $30^{\circ} \mathrm{S}$, the middle ones a doubling of the winds north of $30^{\circ} \mathrm{S}$ and the bottom ones a doubling of all winds in the symmetric wind case, thus a combination of the two other anomaly cases. Figure 16: Net northward heat transport in $10^{15} \mathrm{~W}$ for the three basins. The figure is analogous to the right panel of Fig. 7, but shows all the different wind cases for normal wind strength. 

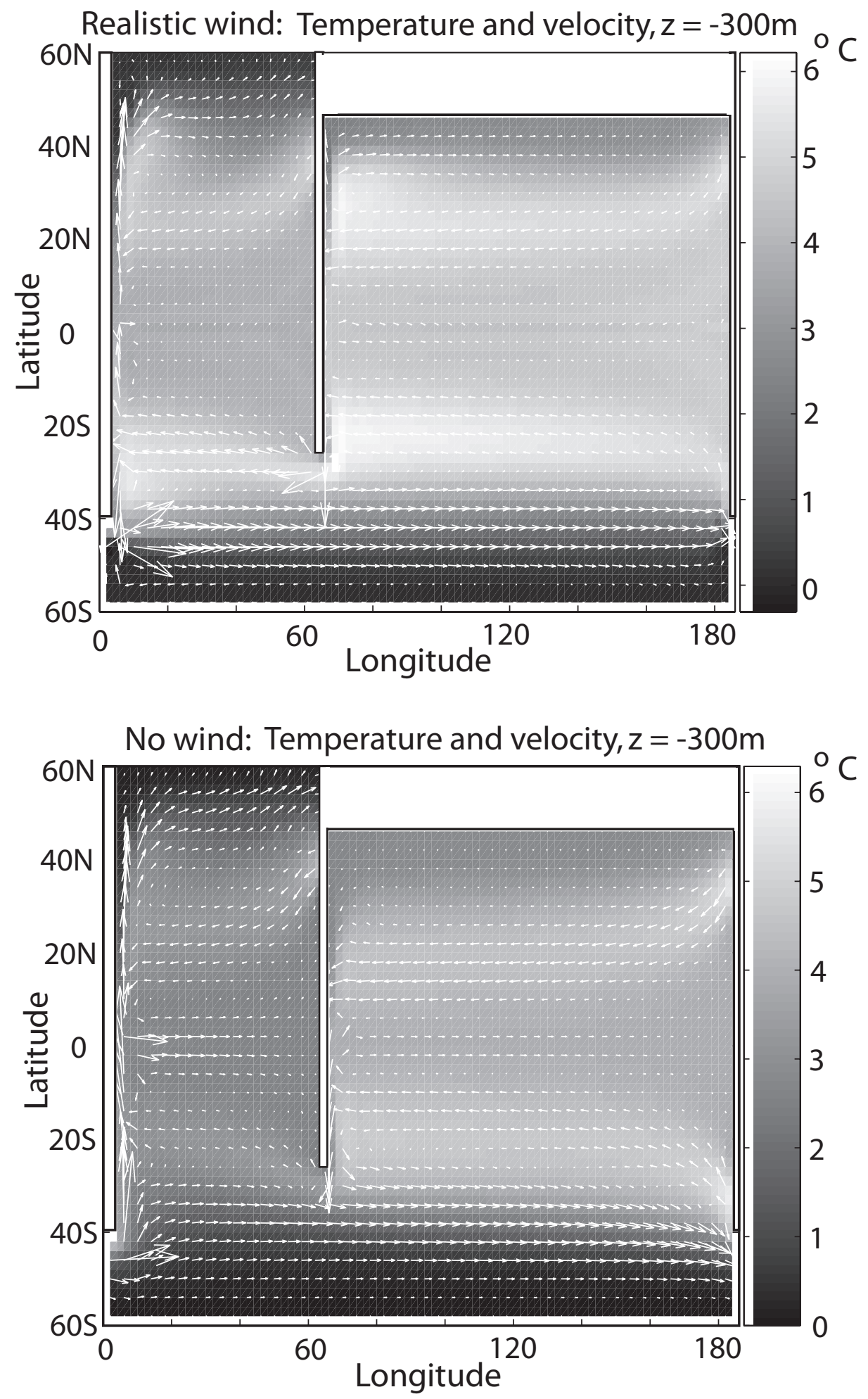

Figure 1. Temperature, in gray scale, and velocity vectors, at 300 meters depth for the realistic wind profile case and the case with no wind. In the idealized model, the narrow and wide basins are referred to as the "Atlantic and the "Pacific", respectively. The north-south land barrier extending furthest southward is "America"; the other one is "Africa", which 'tip" is located roughly at $20^{\circ}$ south. 

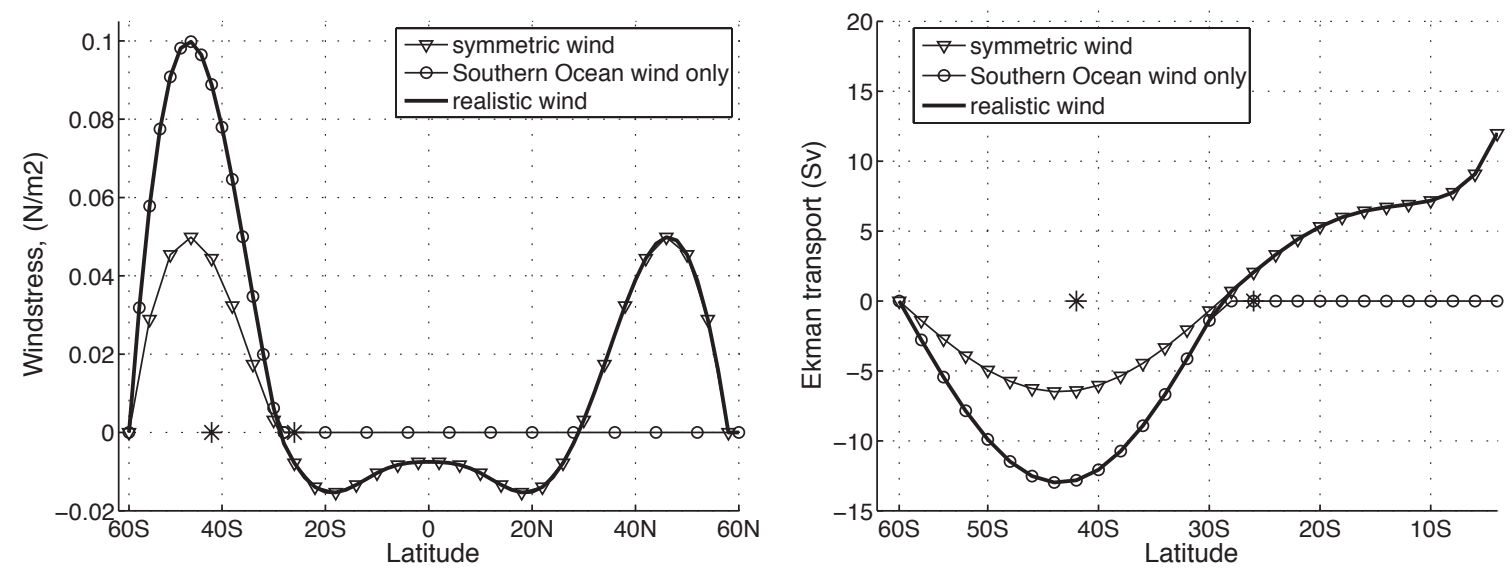

Figure 2. Left panel: Zonal component of the wind stress in $N / \mathrm{m}^{2}$, as a function of latitude. The three cases are; a wind profile with realistic proportions from climatology by Hellerman and Rosenstien (1983) denoted "realistic" wind, symmetric wind and only wind over the Southern Ocean. The two stars indicates the positions of the end of Drake passage and the tip of the "African" continent. Right panel: the Ekman transport in Sverdrups for the three wind cases. 


\section{a. Global}

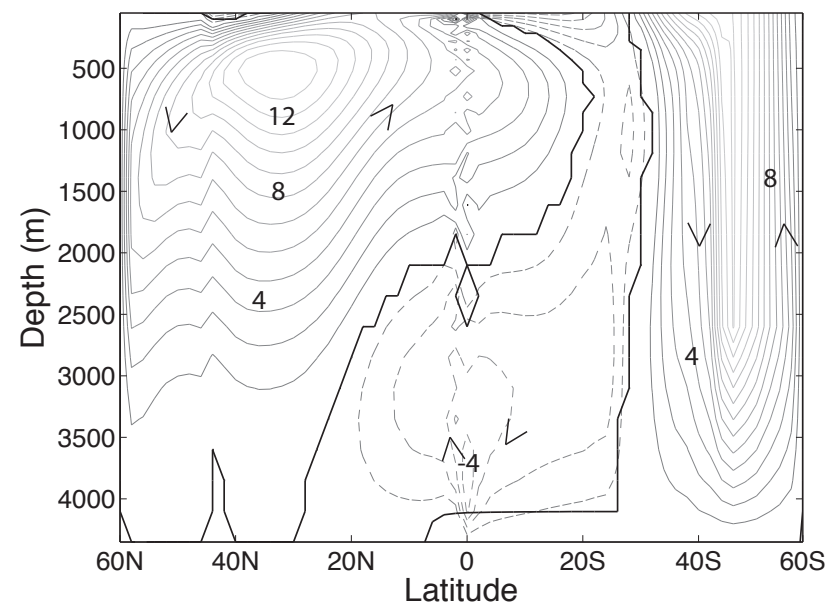

\section{b. Atlantic}

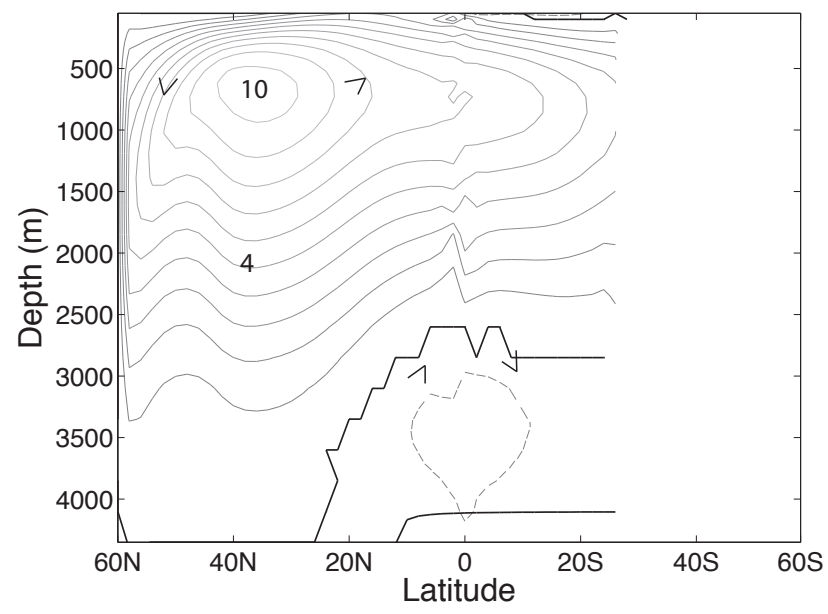

c. Indo-Pacific

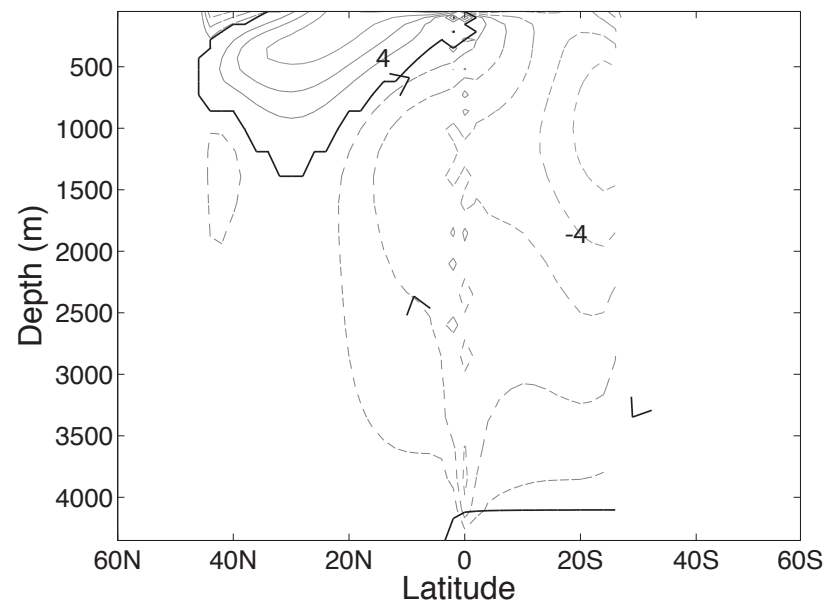

Figure 3. The meridional overturning stream function for the "realistic" wind case, for the entire ocean (top), the Atlantic Ocean (middle) and the Indo-Pacific Ocean (bottom). The flow between the streamlines is in Sverdrups. 


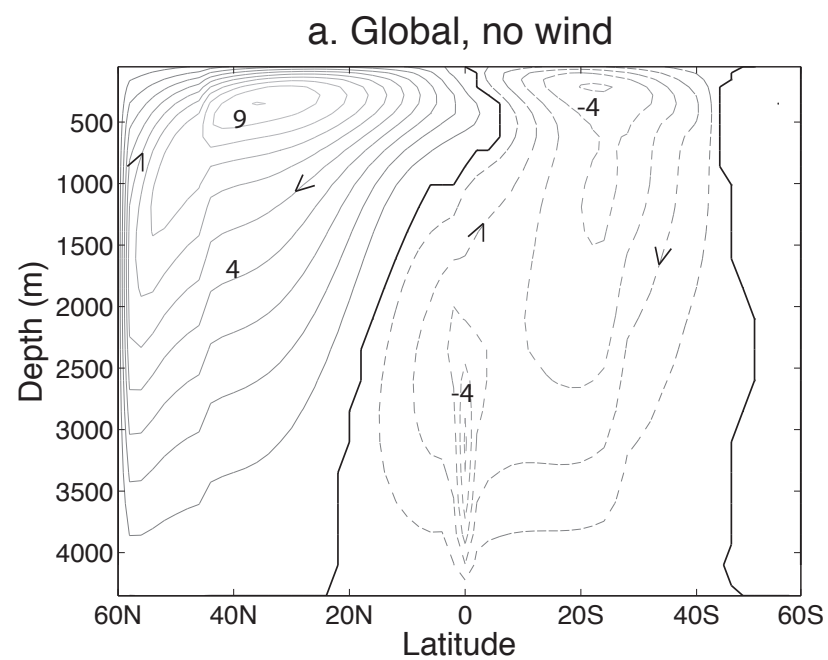

b. Atlantic, no wind

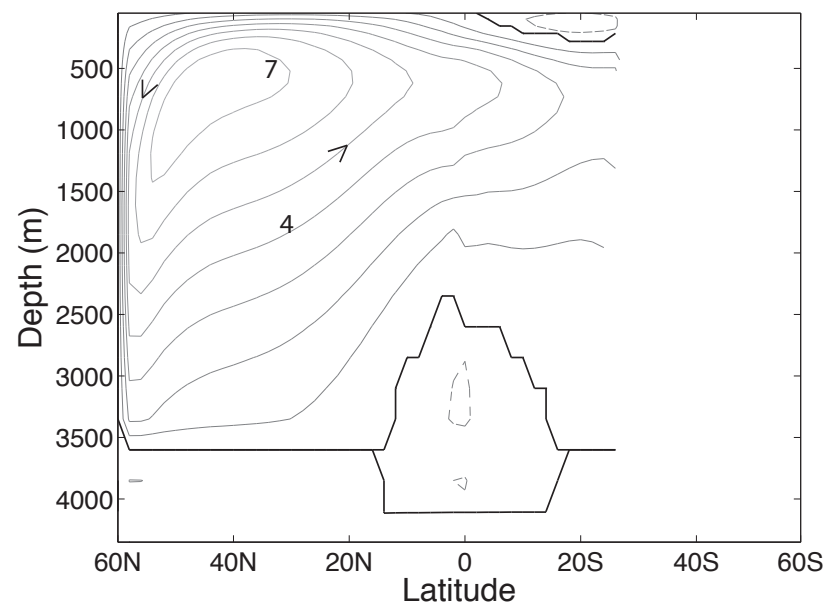

c. Indo-Pacific, no wind

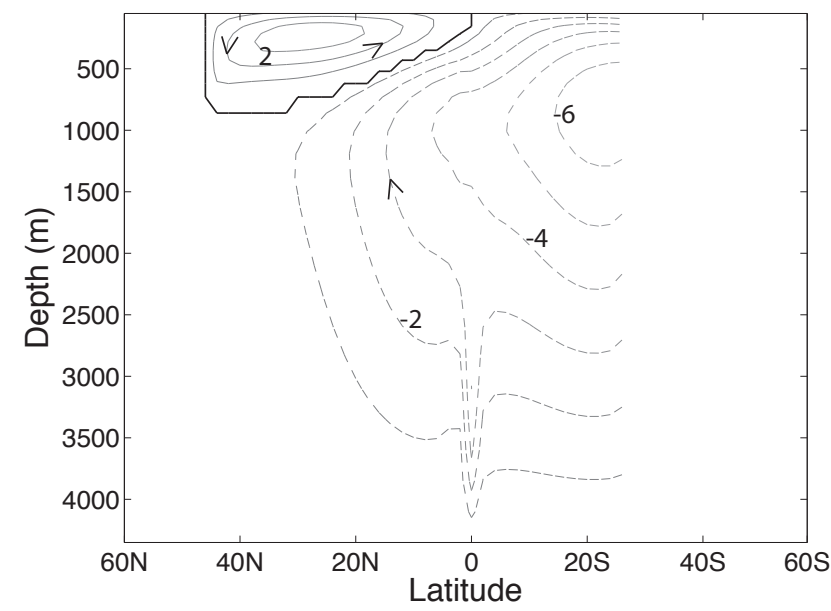

Figure 4. The meridional overturning stream function for the case with no wind. The entire ocean (top), the Atlantic Ocean (middle) and the Indo-Pacific Ocean (bottom). The flow between the streamlines is in Sverdrups. 


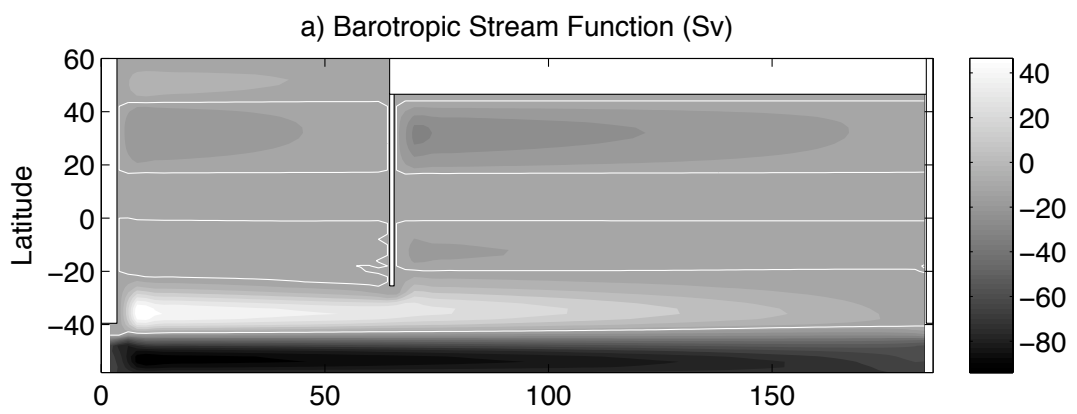

b) Surface Height (m)

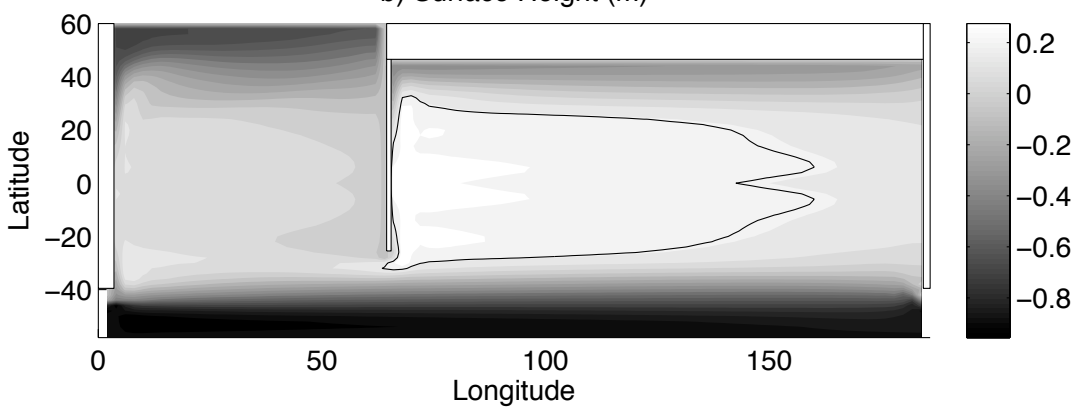

Figure 5. The barotropic stream function (panel a), in units of Sverdrup, and the sea surface height (panel b), in units of meter, for the "realistic" wind case. In a) positive values implies counter clockwise flow and the zero contours are indicated with white lines. To highlight "Agulhas" retroflection, the 0.2 meter contour is indicated with a black line in panel b. 

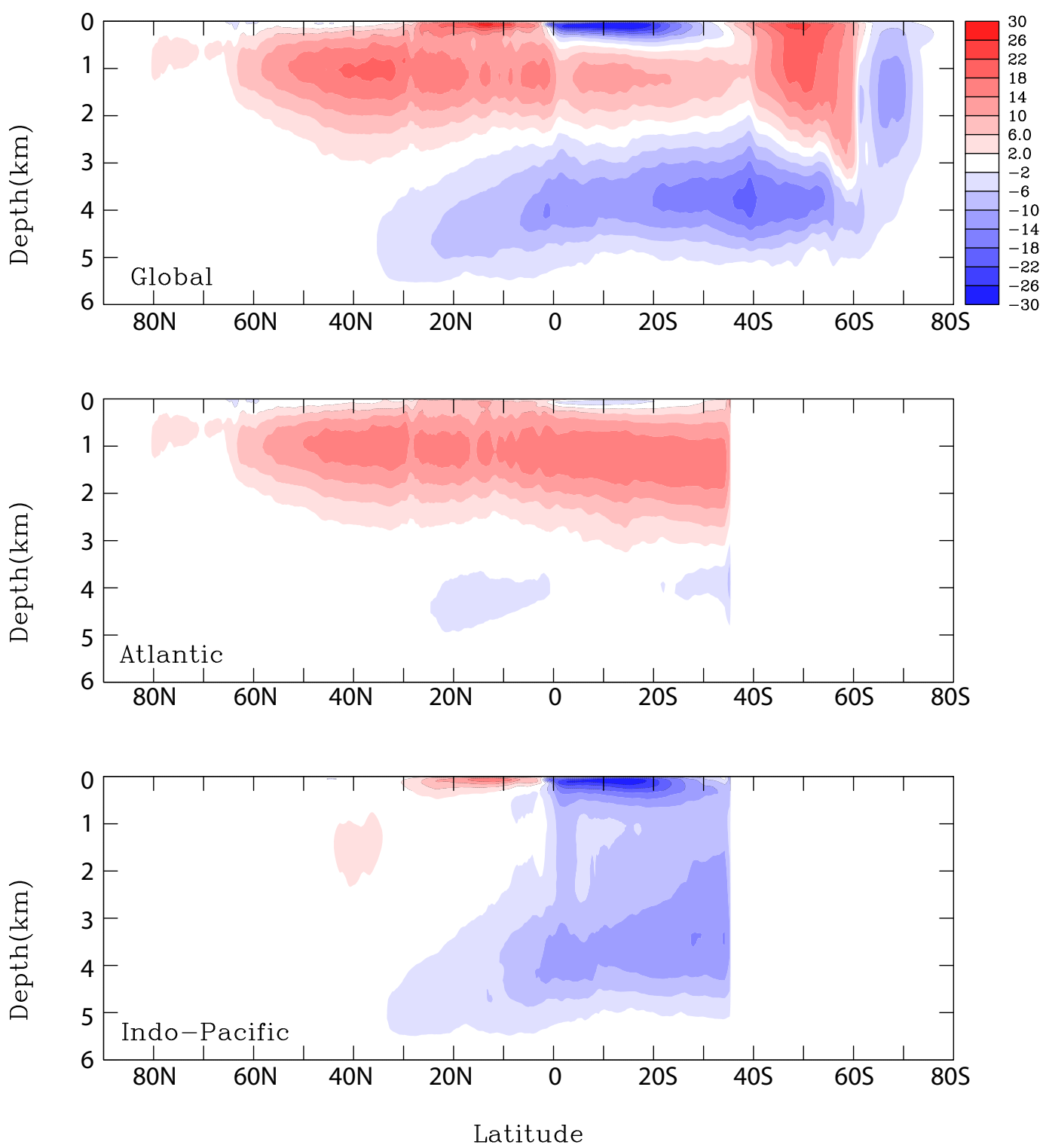

Figure 6. The meridional overturning stream function simulated by OCCAM. The figure shows the average of all stream functions calculated for the 5 days fields from 1991-2002. The transport between the streamlines is in Sverdrups. 

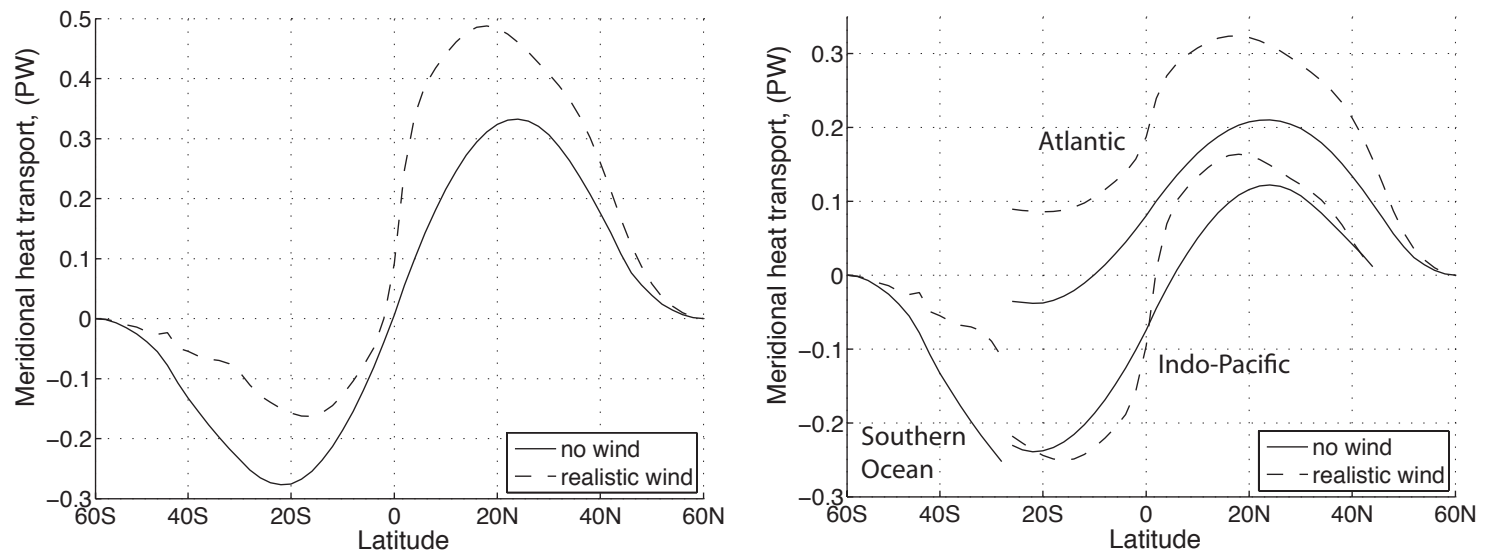

Figure 7. Net northward heat transport in PW $\left(10^{15} \mathrm{~W}\right)$. The left panel shows the total transport for the whole model ocean in the realistic wind case compared to the case with no wind. The right panel shows the same cases but divided into the sub-basins. 

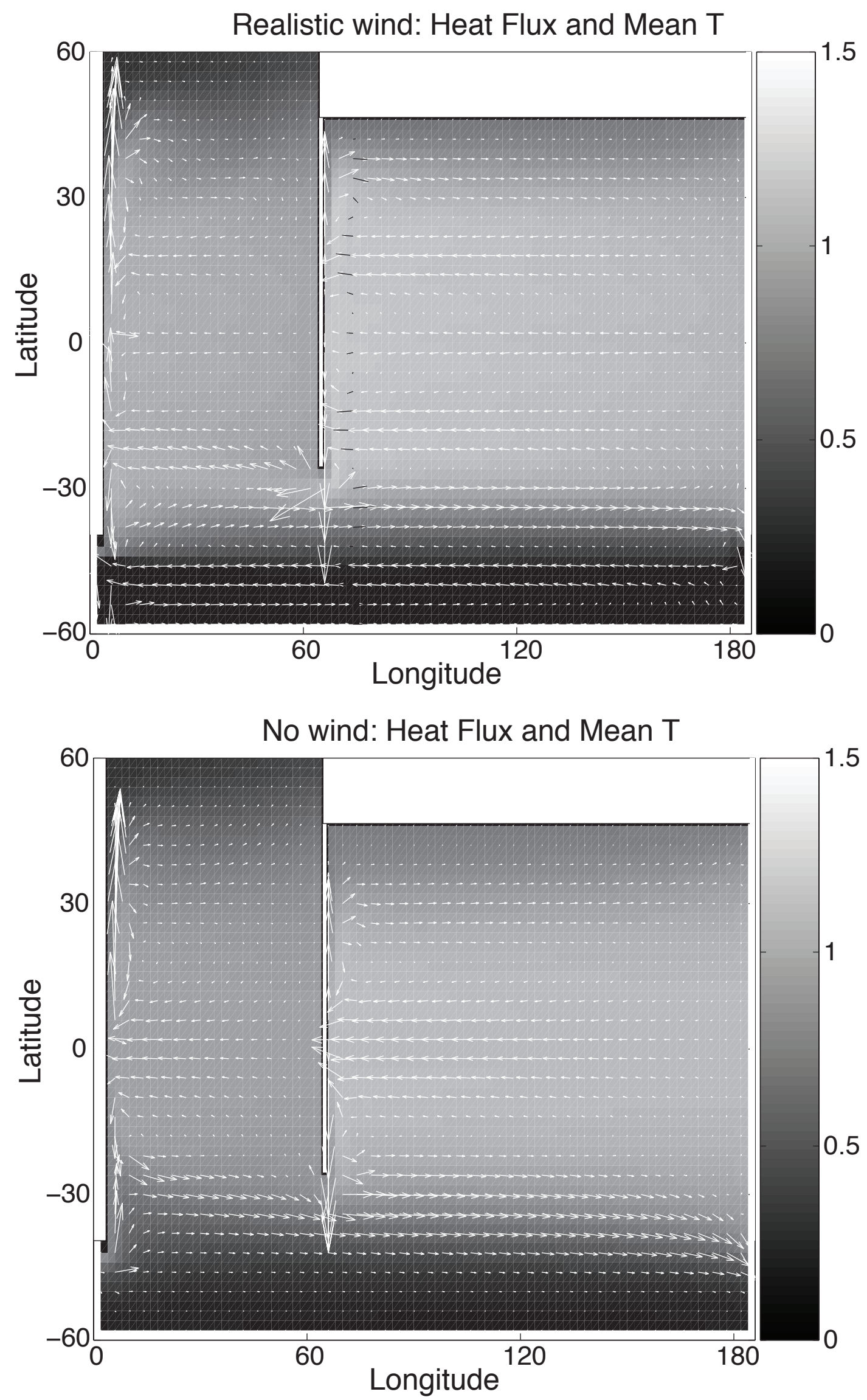

Figure 8. The horizontal heat flux $\mathbf{F}$, as defined by Eq. (3), (vectors) and the vertically-averaged temperature in ${ }^{\circ} \mathrm{C}$ (gray

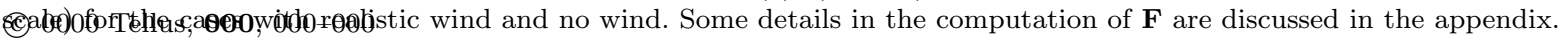



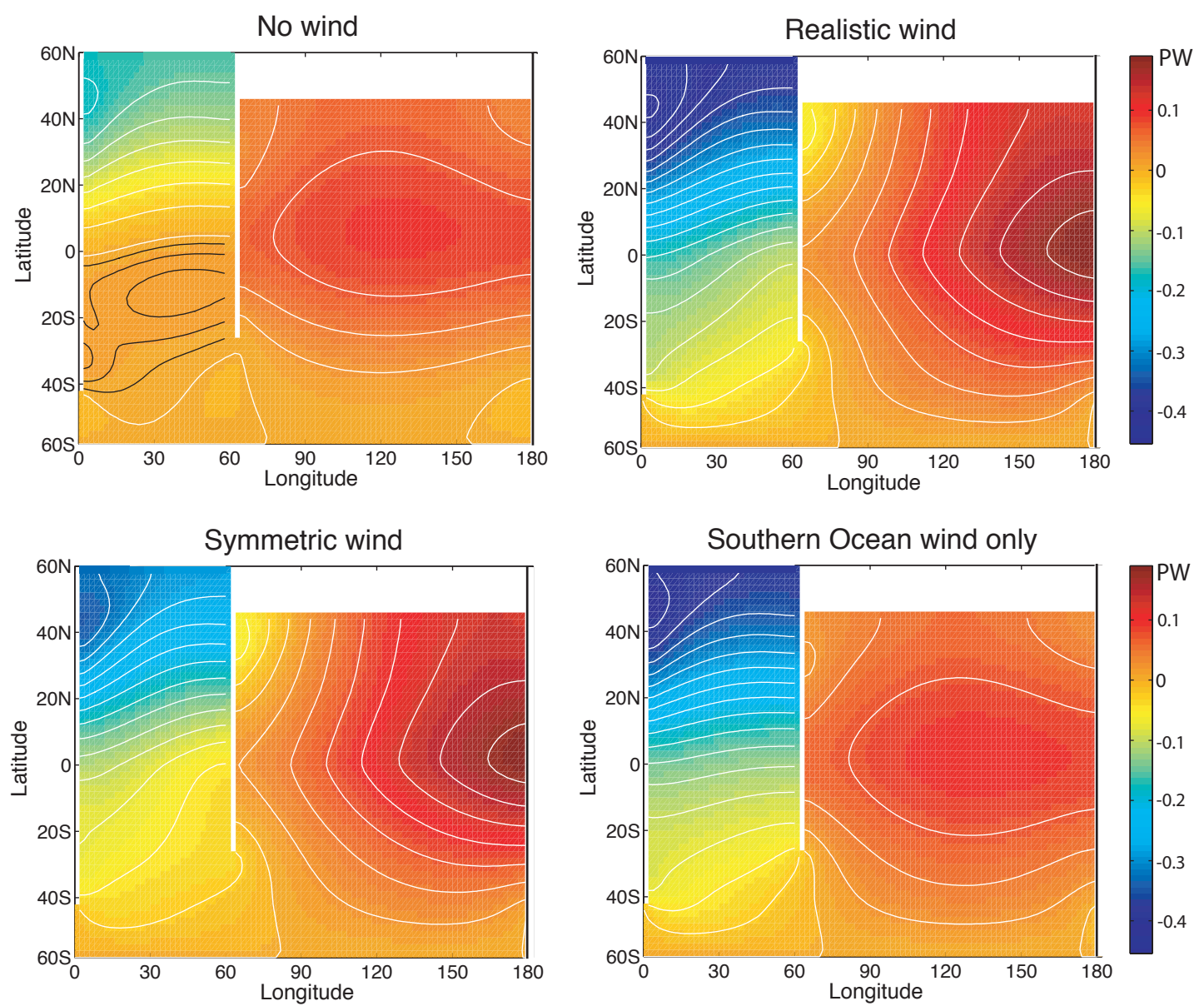

Figure 9. The divergent heat potential fields $\phi$ for the reference case with no wind, and the three different wind cases, in PW $\left(10^{15} \mathrm{~W}\right)$. It is $0.025 \mathrm{PW}$ between the white lines. To keep the same colour scale between the figures of the different wind cases some of the features of the "no wind"-case is lost. To enhance the pattern in the South Atlantic some additional potential lines have been added in panel (a). They are shown in black, and are $5 \mathrm{TW}\left(10^{12} \mathrm{~W}\right)$ apart. 


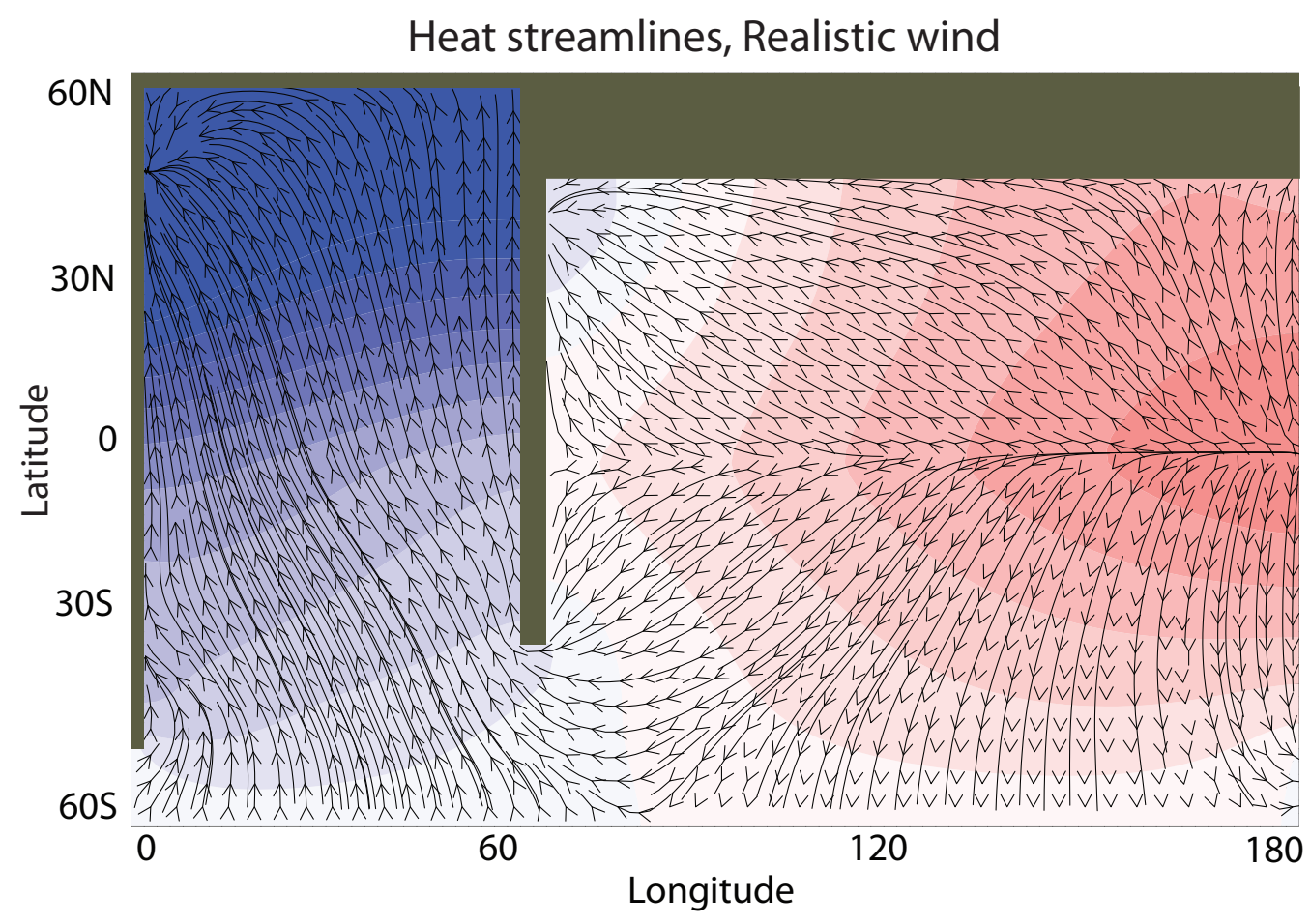

Heat streamlines, No wind

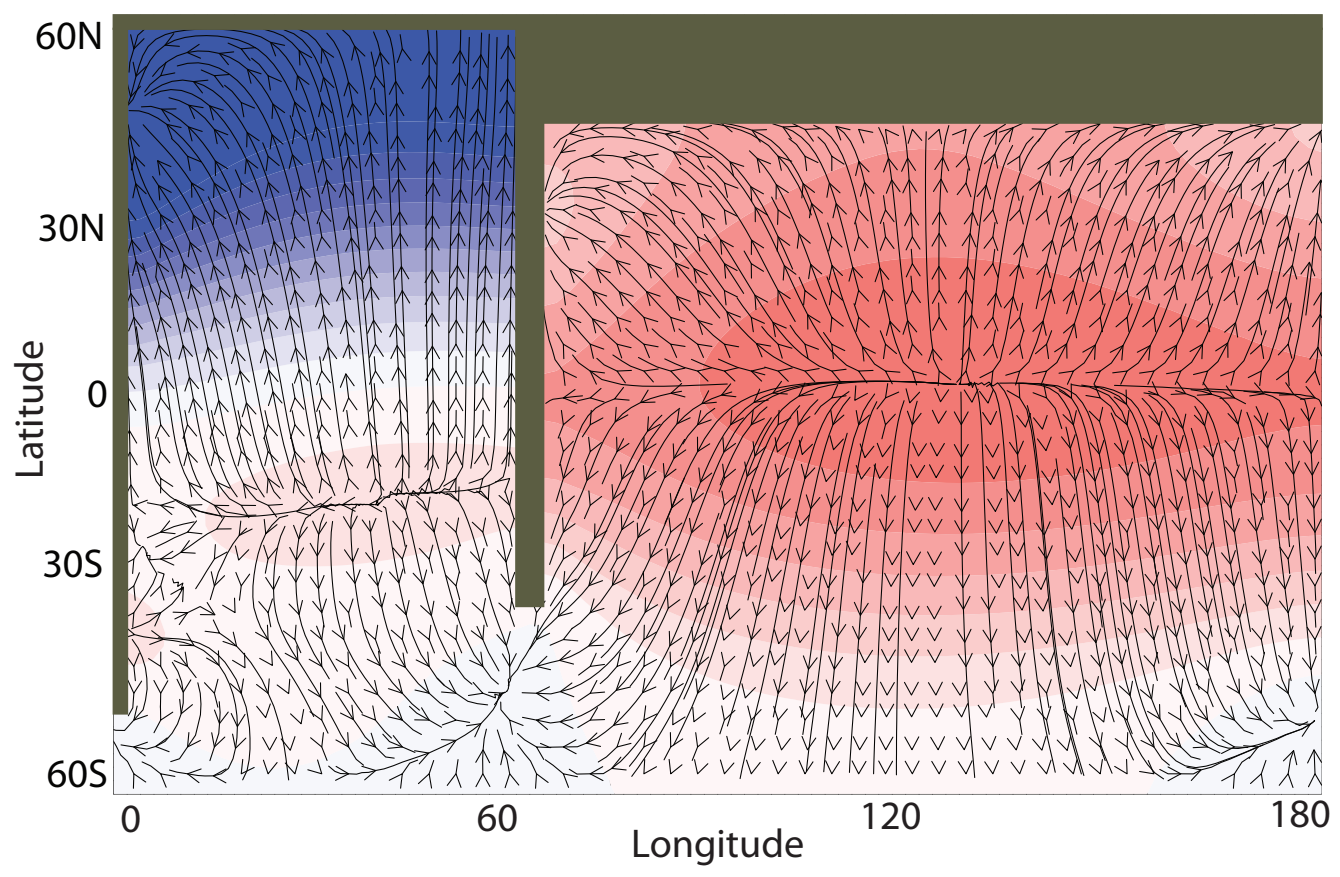

Figure 10. Heat streamlines plotted in the heat potential fields for the the case with realistic wind, and the reference case with no wind. The potential fields are the same as in the top panels in Fig. 9. 

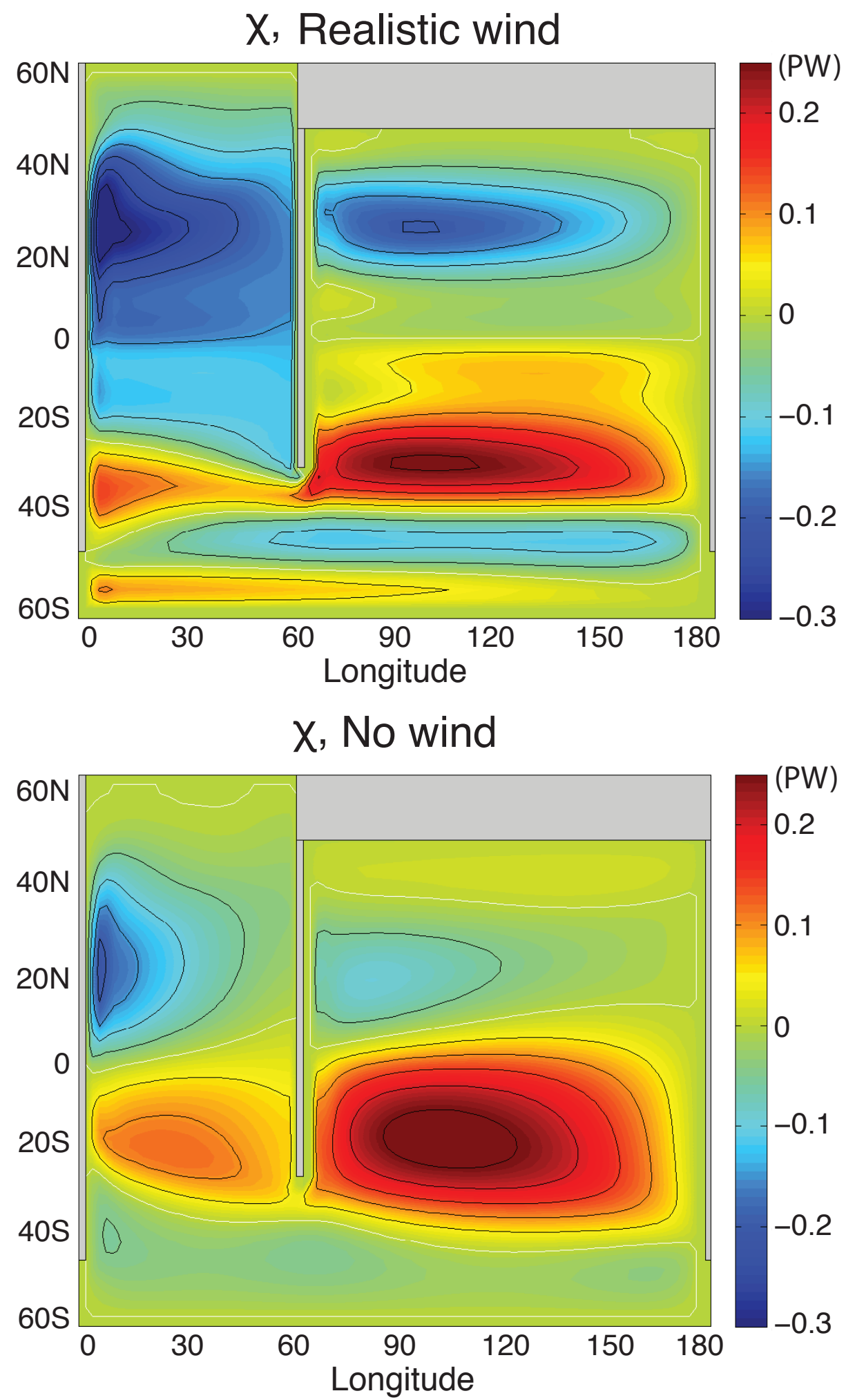

Figure 11. The non-divergent horizontal heat flux streamfunction $\chi$ in PW $\left(10^{15} \mathrm{~W}\right)$; see Eqs. $(4,7)$ and the text for details. Negative/positive values indicate clockwise/anticlockwise flow direction, $0.05 \mathrm{PW}$ between the contour lines. 


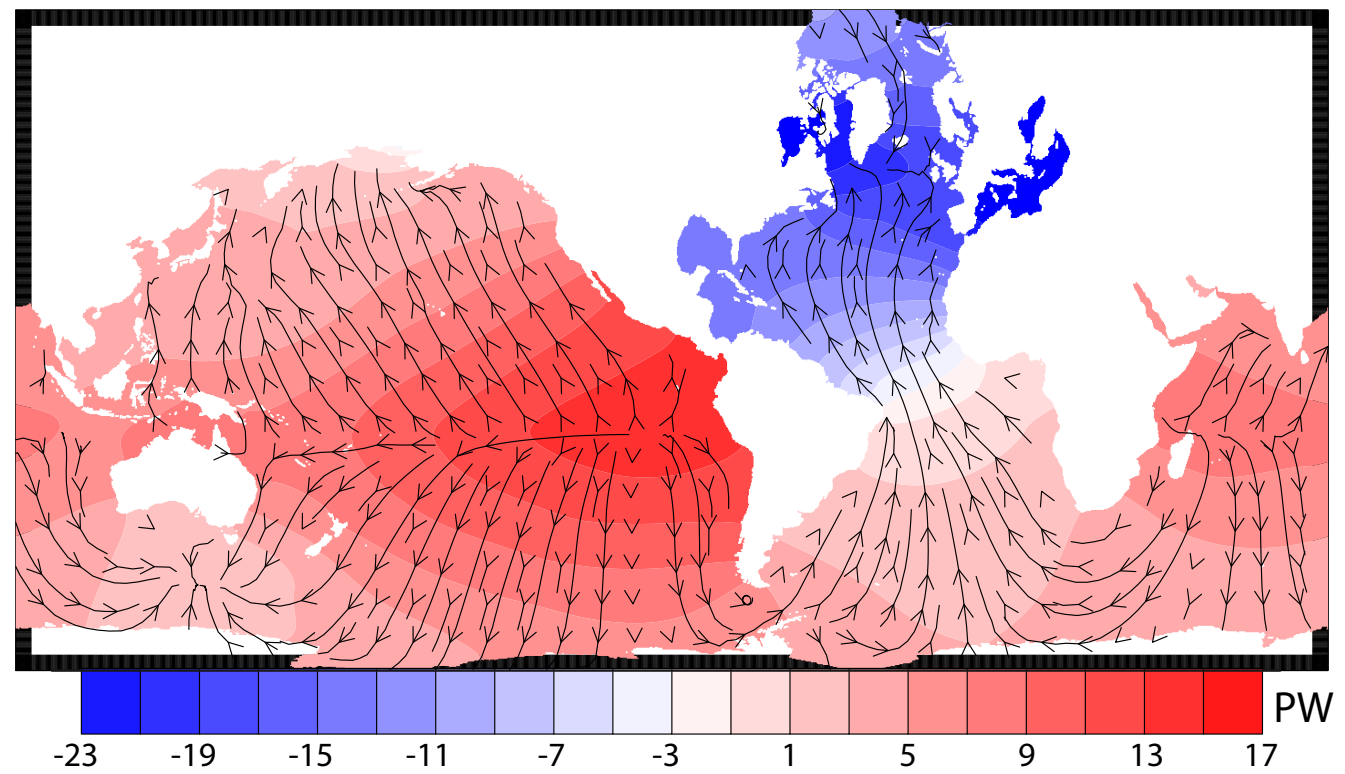

Figure 12. Heat streamlines plotted in the heat potential field from the OCCAM model, for the year 1992.
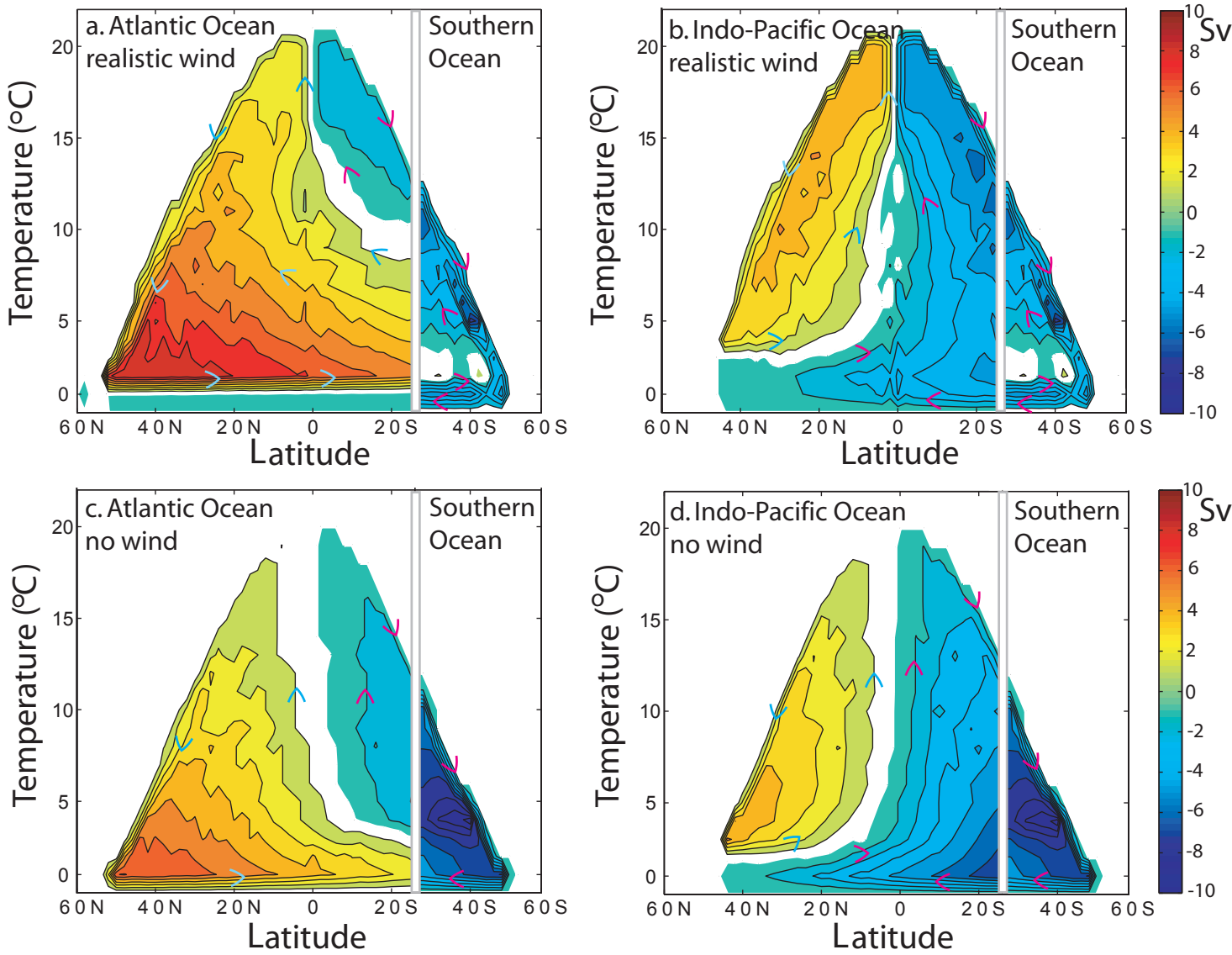

Figure 13. Temperature-latitude stream functions for the case with realistic wind (top) and the reference case with no wind (bottom). The panels to the left show the Atlantic and the Southern Ocean and, the right panels show the Indo-Pacific and the same plots of the Southern Ocean. The color scale displays the flow in Sverdups, and it is 0.5 Sv between the stream lines. 

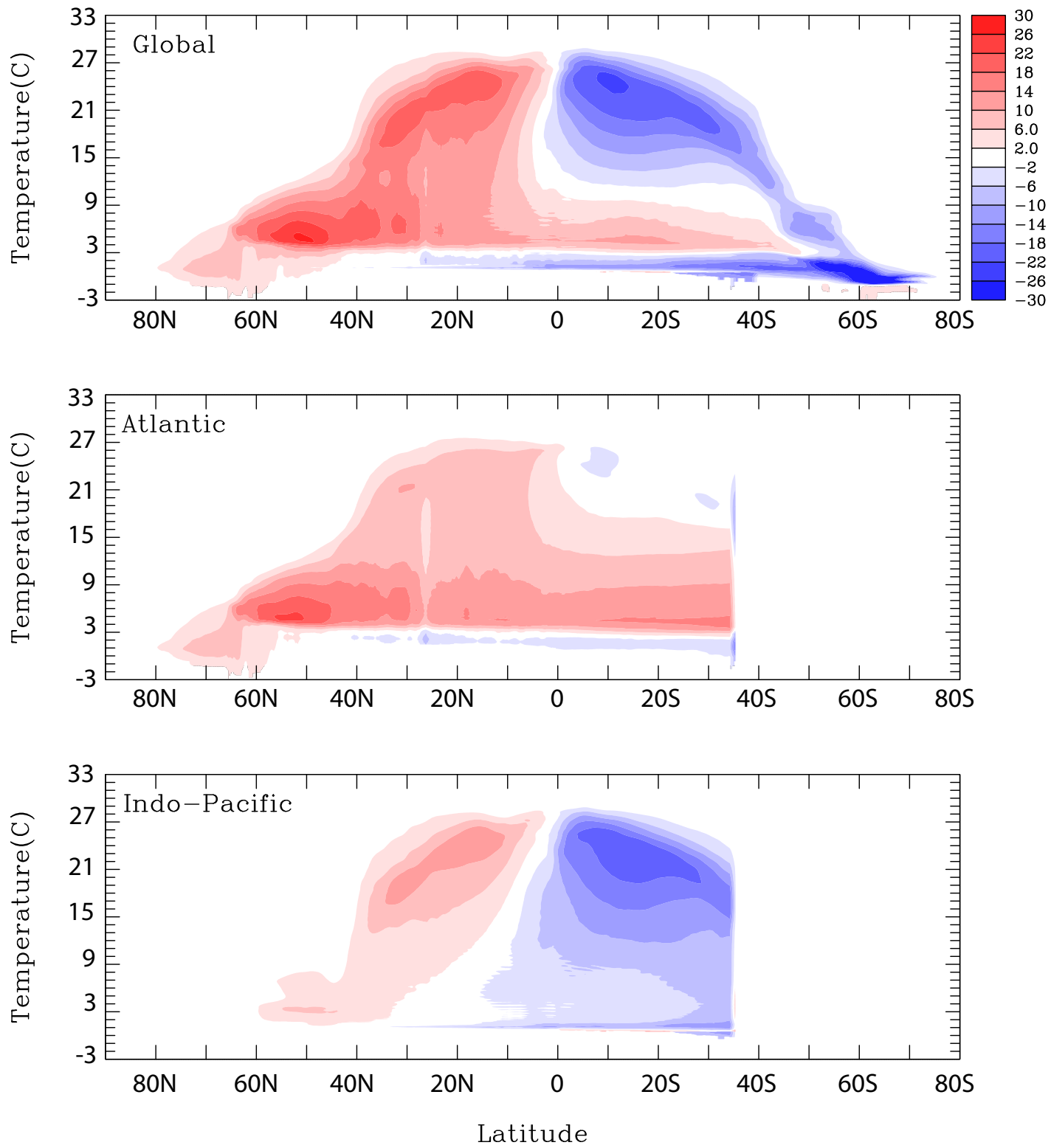

Figure 14. Temperature-latitude stream functions for the OCCAM model. The figure shows the average of all stream functions calculated for the 5 days fields from 1991-2002. It is 4 Sverdrups between the stream lines. 


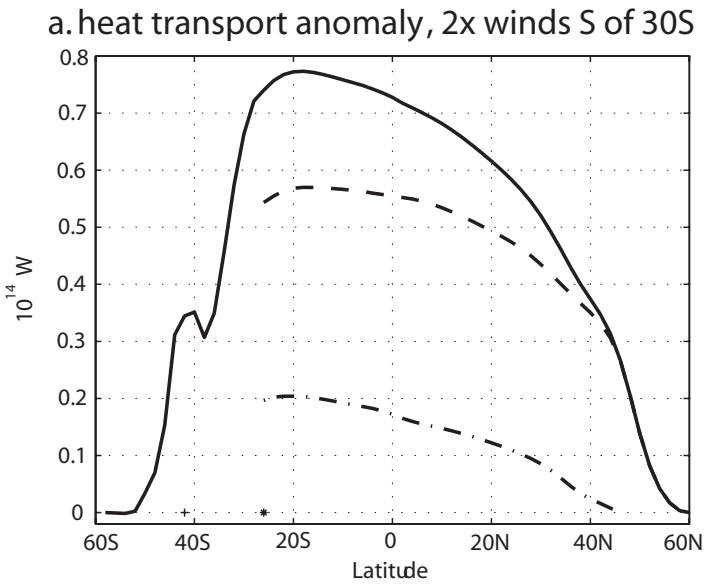

b. heat flux potential anomaly, $2 x$ winds $S$ of $30 \mathrm{~S}$

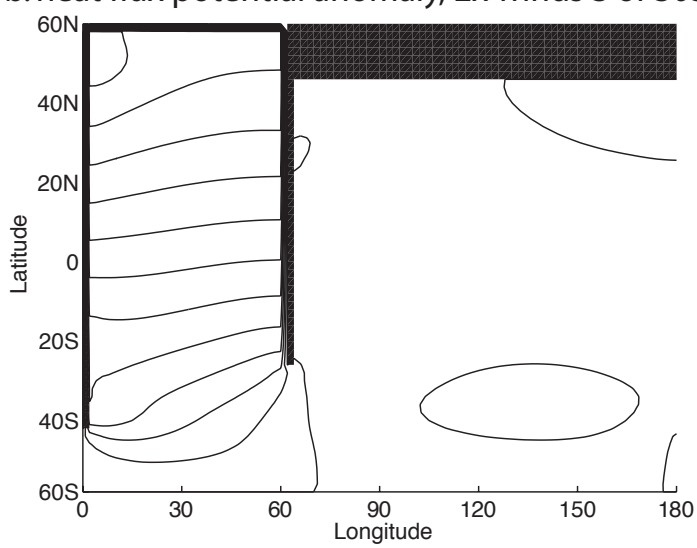

c. heat transport anomaly, $2 \mathrm{x}$ winds $\mathrm{N}$ of $30 \mathrm{~S}$

d. heat flux potential anomaly, $2 x$ winds $\mathrm{N}$ of $30 \mathrm{~S}$
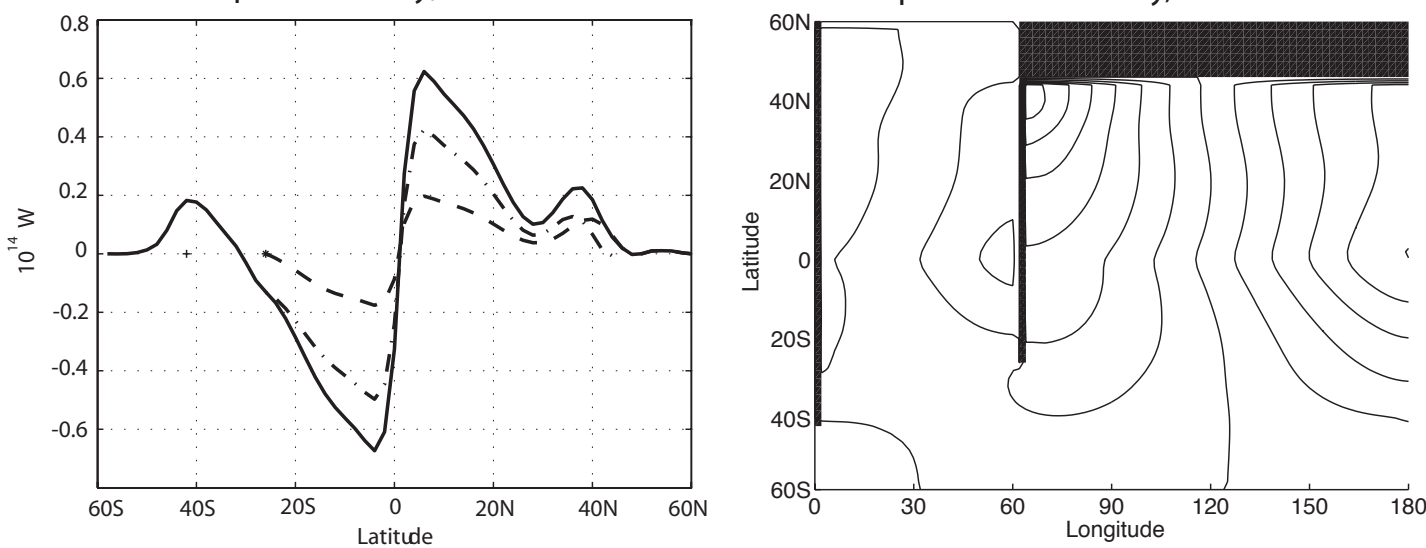

e. heat transport anomaly, 2x sym. winds
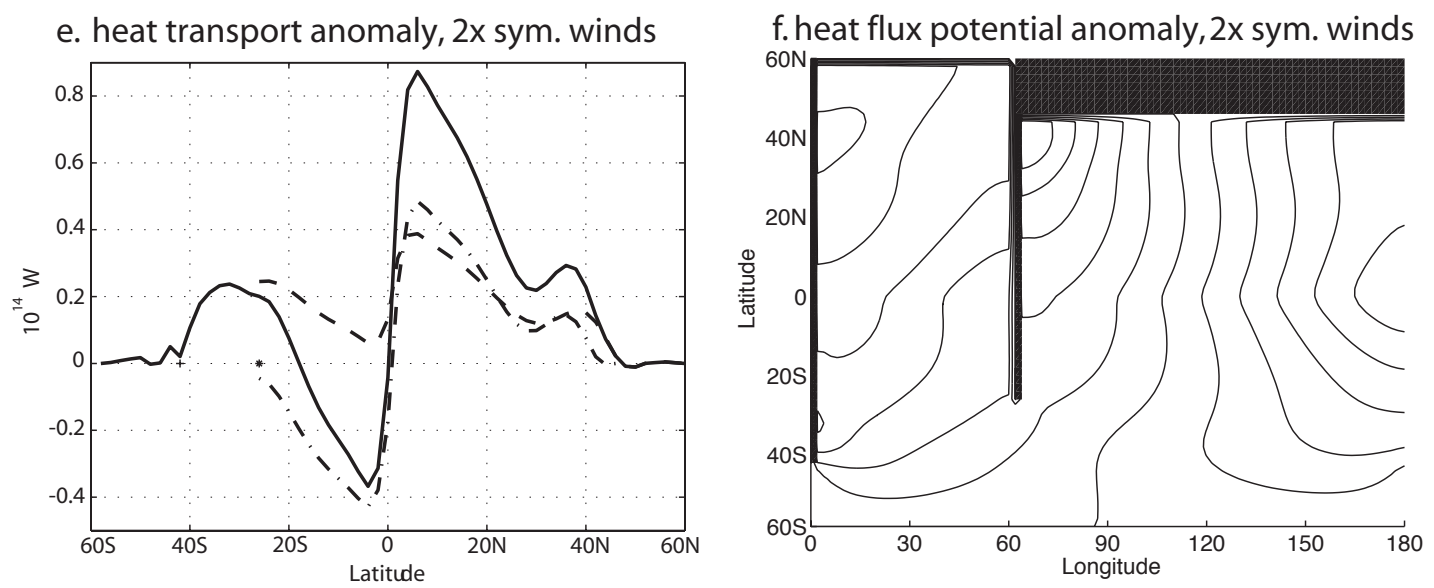

Figure 15. Anomalies in the meridional heat transport, in $10^{14} \mathrm{~W}$, and the heat potential fields, with $0.1 * 10^{14} \mathrm{~W}$ between the potential lines. For the meridional heat transport, the solid, dashed, and dashed-dotted lines represent the total, Atlantic and Indo-Pacific anomalies, respectively. The top panels are the anomalies for a doubling of the wind south of $30^{\circ} \mathrm{S}$, the middle ones a doubling of the winds north of $30^{\circ} \mathrm{S}$ and the bottom ones a doubling of all winds in the symmetric wind case, thus a combination of the two other anomaly cases. 


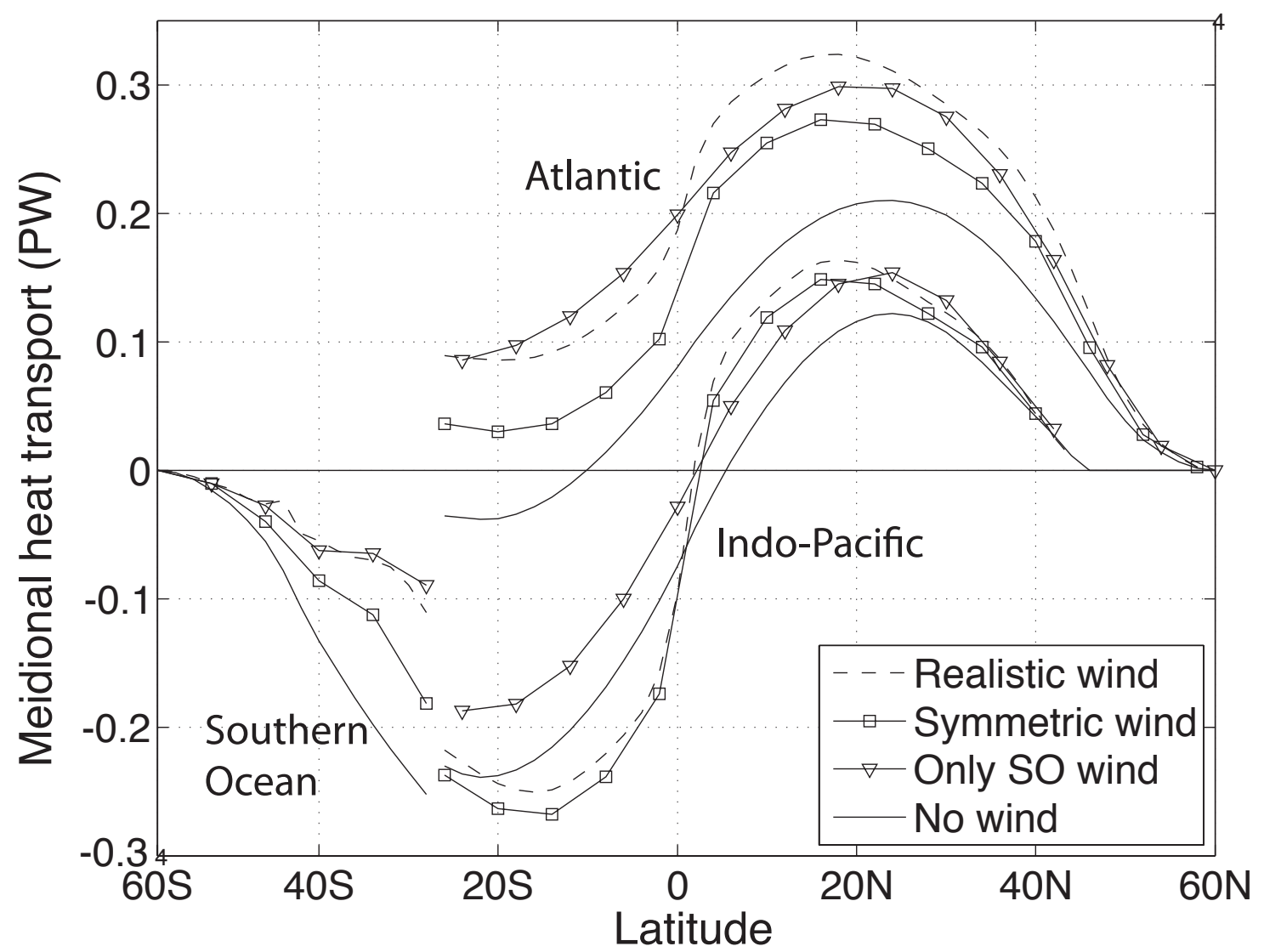

Figure 16. Net northward heat transport in $10^{15} \mathrm{~W}$ for the three basins. The figure is analogous to the right panel of Fig. 7 , but shows all the different wind cases for normal wind strength. 